\title{
Bleaching resistant corals retain heat tolerance following acclimatization to environmentally distinct reefs
}

Katie L. Barott ${ }^{1 *}$, Ariana S. Huffmyer ${ }^{2,3}$, Jennifer M. Davidson ${ }^{2}$, Elizabeth A. Lenz ${ }^{2,4}$, Shayle B. Matsuda $^{2}$, Joshua R. Hancock ${ }^{2}$, Teegan Innis ${ }^{1}$, Crawford Drury ${ }^{2}$, Hollie M. Putnam ${ }^{3}$, Ruth D. Gates $^{2}$

${ }^{1}$ Department of Biology, University of Pennsylvania, Philadelphia, PA 19104 USA

${ }^{2}$ Hawai'i Institute of Marine Biology, University of Hawai' $i$, Mānoa, HI 96744 USA

${ }^{3}$ Department of Biological Sciences, University of Rhode Island, Kingston, RI 02881 USA

${ }^{4}$ Sea Grant College Program, University of Hawai'i i at Mānoa, HI, 96822 USA

${ }^{*}$ Corresponding author: Katie L. Barott, kbarott@sas.upenn.edu

Key words: climate change, coral bleaching, coral-algal symbiosis, assisted gene flow, assisted evolution, ocean acidification, ocean warming

Running Title: Coral stress resistance after acclimatization

\begin{abstract}
:
Urgent action is needed to prevent the demise of coral reefs as the climate crisis leads to an increasingly warmer and more acidic ocean. Propagating climate change resistant corals to restore degraded reefs is one promising strategy; however, empirical evidence is needed to determine if resistance is retained following transplantation within or beyond a coral's natal reef. Here we assessed the performance of bleaching-resistant individuals of two coral species following reciprocal transplantation between environmentally distinct reefs (low $v s$ high diel variability) to determine if stress resistance is retained following transplantation. Critically, transplantation to either environment had no influence on coral bleaching resistance, indicating that this trait was relatively fixed and is thus a useful metric for selecting corals for reef restoration within their native range. In contrast, growth was highly plastic, and native performance was not predictive of performance in the novel environment. Coral metabolism was also plastic, with cross transplants of both species matching the performance of native corals at both reefs within three months. Coral physiology (autotrophy, heterotrophy, and metabolism) and overall fitness (survival, growth, and reproduction) were higher at the reef with higher flow and fluctuations in diel $\mathrm{pH}$ and dissolved oxygen, and did not differ between native corals and cross-transplants. Conversely, cross-transplants at the low-variability reef had higher fitness than native corals, thus increasing overall fitness of the recipient population. This experiment was conducted during a non-bleaching year, which suggests that introduction of these bleachingresistant individuals will provide even greater fitness benefits to recipient populations during bleaching years. In summary, this study demonstrates that propagating and transplanting bleaching-resistant corals can elevate the resistance of coral populations to ocean warming while simultaneously maintaining reef function as the climate crisis worsens.
\end{abstract}




\section{Introduction}

The global climate crisis is threatening the survival of coral reef ecosystems around the world. As climate change increases the temperature of the world's oceans (Johnson and Lyman 2020), marine heatwaves are becoming increasingly frequent (Frölicher et al. 2018) and leading to widespread coral bleaching (Hughes, Anderson, et al. 2018), a heat stress response where the coral-algal symbiosis breaks down and the algae (dinoflagellates in the family Symbiodiniaceae) are expelled from the host (Jokiel 2004; Oakley and Davy 2018). This dysbiosis has a myriad of negative consequences, ranging from declines in coral growth and reproduction to extensive coral mortality (Ward et al. 2000; Baird and Marshall 2002; Baker et al. 2008; Hughes, Kerry, Baird, et al. 2019; Hughes, Kerry, et al. 2018). These bleaching-associated outcomes affect the function of the entire reef ecosystem, as coral biomineralization is necessary to build and maintain the physical framework that is required to support the immense biodiversity typical of a healthy coral reef (Fordyce et al. 2019; Leggat et al. 2019; Hughes, Kerry, Connolly, et al. 2019). Deterioration of the reef structure is also being exacerbated by the other climate change stressor, ocean acidification (Doney et al. 2009), which has also led to declines in net ecosystem calcification (Eyre et al. 2018; Andersson and Gledhill 2013; Albright et al. 2016). An important ongoing question is whether coral populations have the capacity to acclimatize or adapt to these two climate change stressors fast enough to avoid catastrophic losses (Edmunds and Gates 2008), and whether human intervention can enhance this process to help corals keep pace with a rapidly changing environment (Van Oppen et al. 2015). Encouragingly, there is evidence that coral populations are becoming more resistant to bleaching during heat stress (Sully et al. 2019; Coles et al. 2018). However, this nominal improvement may be coming at the expense of certain species, as only the more tolerant taxa remain following the selective sieve of major bleaching mortality events (Hughes, Kerry, et al. 2018; Loya et al. 2001; McClanahan 2004; Edmunds 2018).

Action is clearly needed to mitigate widespread mortality of coral reefs predicted over the next century given business as usual carbon emissions. There has been a surge in discussions over the last few years on the implementation of adaptive management strategies such as selective propagation of climate change resistant corals (e.g. via assisted gene flow, selective 75 breeding) to prevent the extinction of reefs and species (Van Oppen et al. 2015, 2017; Anthony 
individuals with desired phenotypes (e.g. rapid growth, bleaching resistance) for coral reef recovery and restoration is a promising approach; however, the utility of these scientifically informed efforts depends not only on the survival of coral transplants, but also the retention of selected traits (e.g. rapid growth, bleaching resistance) following transplantation to novel physicochemical and ecological conditions and their integration into the population. Determining the feasibility of these approaches therefore requires improved knowledge of the fundamental mechanisms of coral acclimatization, since we do not know if, or for how long, these phenotypes are retained following exposure to novel environmental regimes within or across generations. Rigorous experimental evaluation is therefore needed to address this question, and the results of which are important not only for restoration, but also for understanding the capacity for coral populations to withstand rapid environmental change resulting from anthropogenic activities.

A first step in testing whether bleaching resistance is the result of local adaptation or acclimatization is to identify bleaching resistant individuals with higher temperature thresholds for bleaching within a population. These corals are often found in locations with higher mean temperatures (e.g. shallow inshore reefs with restricted water flow, (Jokiel and Brown 2004; Woesik et al. 2012; Castillo and Helmuth 2005), or those with larger magnitude or higher frequency fluctuations in temperature than surrounding reefs (Oliver and Palumbi 2011; Palumbi et al. 2014; Schoepf et al. 2015; Safaie et al. 2018), though not always (Klepac and Barshis 2020). Reefs with conditions that promote these local threshold maxima are likely excellent resources for selecting the most bleaching resistant genets of the various species found in a region, but only if elevated heat tolerance is retained when environmental conditions change. It is therefore critical to understand the biological mechanisms by which these environmental conditions influence coral bleaching thresholds, either by acclimatization or adaptation, as these mechanisms influence the persistence of adaptive traits through time and space (Drury 2020).

101 For example, seasonal acclimatization can temporarily elevate local bleaching thresholds when

102 peak temperatures are preceded by brief sub-bleaching heat pulses, essentially priming corals to 103 tolerate subsequent heat stress (Ainsworth et al. 2016; Sully et al. 2019), though it appears such

104 intra and cross-generational priming benefits can be temporary (Putnam et al. 2020). Coral

105 bleaching events provide an opportunity to identify bleaching resistant individuals within a 106 population, and have the advantage of allowing assessment of relative performance between 107 individuals of the same species, in a natural context. 
Here, we identified bleaching resistant individuals (i.e. corals that did not bleach during the second of two coral bleaching events that occurred in the span of two years in the Main

110 Hawaiian Islands in 2015; Matsuda et al. 2020) of two important reef-building species,

111 Montipora capitata and Porites compressa. After monitoring these corals for one year following

112 the bleaching event, we tested the effects of acclimatization to a novel physicochemical

113 environment on their bleaching resistance and fitness by reciprocally transplanting ramets of

114 each colony between two patch reefs in Kāne`ohe Bay, O`ahu, Hawai'i with contrasting

115 environmental conditions. In addition, the physiological plasticity of each species was examined

116 by measuring coral survival, growth, metabolism, tissue energetics, and feeding rates in their

117 native vs. cross-transplanted environments at 3- and 6-months post-transplantation. These

118 experiments are a critical step towards understanding the biological basis and utility of selecting

119 and propagating climate change resistant corals for enhancing coral reef resilience to climate 120 change.

\section{Materials and Methods}

\section{Experimental Design}

Site selection and characterization: Kāne'ohe Bay contains a network of coral-dominated

126 fringing and patch reefs (Fig. 1A). These reefs are protected from wave action by a barrier reef

127 that generates a gradient of seawater residence times (Lowe et al. 2009) and thus a spatial

128 gradient in physicochemical conditions (e.g. magnitude of diel $\mathrm{pH}$ and $\mathrm{pCO}_{2}$ fluctuations;

129 (Massaro et al. 2012; Drupp et al. 2013; Page et al. 2018). Here we targeted two patch reefs

130 representing distinct physicochemical conditions: 1) an Inner Lagoon (IL) reef $\left(21.4343^{\circ} \mathrm{N}\right.$,

$131 \quad 157.7991^{\circ} \mathrm{W}$ ) with a relatively low-flow and stable $\mathrm{pH}$ environment, and 2) an Outer Lagoon

$132(\mathrm{OL}) \operatorname{reef}\left(21.4516^{\circ} \mathrm{N}, 157.7966^{\circ} \mathrm{W}\right)$ with a relatively high-flow and variable $\mathrm{pH}$ environment

133 (Fig. 1A). In addition to differences in $\mathrm{pH}$ and flow, the IL reef is located nearshore $(0.75 \mathrm{~km})$

134 and is thus exposed to greater terrestrial influence than the OL reef (1.6 km from shore; Fig. 1A).

135 In order to characterize the physicochemical dynamics at each reef, temperature, salinity,

$136 \mathrm{pH}$ and dissolved oxygen (DO) were measured on the reef benthos at each site (2 $\mathrm{m} \mathrm{depth}$ ) and

137 recorded in 15-minute intervals using SeapHOx sensors (SeaBird Electronics). Prior to

138 deployment, the $\mathrm{pH}$ sensors were conditioned in a flow-through seawater aquarium and the DO 
sensors were calibrated using 100\% air-saturated seawater and an anoxic sodium sulfite solution

$140\left(10 \mathrm{mg} \mathrm{ml}^{-1}\right)$. Following deployment, discrete water samples were collected monthly at each site

141 immediately adjacent to the SeapHOx intake at the corresponding time of the instrument

142 sampling. Seawater samples were returned to the lab within 45 minutes of collection and

143 analyzed in triplicate for spectrophotometric $\mathrm{pH}$ measurements using $m$-cresol purple as

144 described by SOP 6b (10 cm path length; Dickson et al. 2007). Photosynthetically active

145 radiation (PAR) was measured in 15-minute intervals using Odyssey PAR loggers (three sensors

146 per site) calibrated to a Licor cosine light sensor. Sedimentation rate at each reef was measured

147 using triplicate sediment traps oriented at $90^{\circ}$ degrees from the bottom and open at the mouth

148 (Storlazzi et al. 2011), which were collected and redeployed every two weeks. Relative rates of

149 water movement at each reef were measured every $2-3$ weeks (9 times total) using the clod-card

150 dissolution technique (6 cards per reef; (Doty 1971; Jokiel and J Morrissey 1993).

Identification of bleaching resistant coral colonies: Bleaching resistant colonies of

153 Montipora capitata (Fig. 1C) and Porites compressa (Fig. 1D) were tagged during the peak of

154 the 2015 coral bleaching event (Matsuda et al. 2020). One year later, ten individuals of each

155 species at each of the two reefs (40 colonies total), with the exception of two $M$. capitata

156 colonies from the OL reef with unknown bleaching history. $M$. capitata colonies were genotyped

157 using microsatellite markers as described in (Concepcion et al. 2010) in order to confirm that

158 clonemates were avoided. Amplification attempts using primers from (Baums et al. 2012) for $P$.

159 compressa were unsuccessful, but individuals sampled were spaced at least $5 \mathrm{~m}$ apart and on

160 average $\sim 20 \mathrm{~m}$ apart on the reef to minimize chances of collecting clones.

Reciprocal transplant: A portion of each of the 40 coral colonies described above was

163 collected in August 2016 under HIMB Special Activities Permit 2016-69. Each colony was

164 fragmented into 80 small $(\sim 4 \mathrm{~cm})$ fragments (Fig. 1B) for use in physiological analyses and were

165 attached to numbered acrylic frag plugs using cyanoacrylate gel. Two larger fragments $\left(\sim 15 \mathrm{~cm}^{2}\right.$;

166 Fig. 1B) per colony were attached to numbered plastic grids using underwater epoxy (A-788

167 Splash Zone Two Part Epoxy) for use in reproduction assays. All coral fragments were mounted

168 on PVC racks ('coral racks'), which were attached to underwater frames at their native reef (Fig.

169 1E-F) within 24 hours of collection. Corals were allowed to recover in situ for $5-7$ days (small 
170 fragments) or $1-4$ days (large fragments) prior to initiation of the reciprocal transplant on

171 August 19, 2016 (Fig. 1C). Half of the fragments from each colony were kept at their origin reef

172 (native site), and half were transplanted to the other reef (cross-transplanted; Fig. 1B). To do so,

173 five replicate fragments per parent colony were randomly distributed onto each of four coral

174 racks at each site by divers, for a total of 100 fragments of mixed origin per rack (5 replicate

175 fragments from each of 20 conspecific parents). For the large coral fragments, 10 conspecific

176 fragments were attached to each coral rack. Coral racks were then haphazardly arranged and

177 secured to the frames (Fig. 1E-F). All coral racks were randomly repositioned along the frames

178 within a site every 6 weeks for the first 6 months of the experiment. After that, only the large

179 coral fragments remained, and these were spread out to 5 corals per rack. The racks were

180 rearranged along the frames within each site monthly until the start of spawning (May 2017).

181 The reciprocal transplant resulted in four transplant histories (i.e. origin $\mathrm{x}$ destination crosses).

\section{Thermal Challenge}

Six months following the reciprocal transplant, a subset of coral fragments ( 2 per genet per transplant history; 160 fragments total) were randomly allocated into an ambient or high temperature treatment group for an acute thermal stress experiment. A total of 8 indoor flowthrough seawater tanks were randomly assigned as ambient and high temperature treatment tanks, and 20 corals were placed in each tank. Each tank was illuminated by an LED aquarium light (Ecotech Marine XR30w Pro) on a 12:12 h light:dark cycle set to mimic the in situ light cycle (peak of $\sim 730 \mu \mathrm{mol} \mathrm{m} \mathrm{m}^{-2} \mathrm{~s}^{-1}$ ). The temperature of each tank was monitored and controlled

191 using a Neptune Apex Aquarium Controller system in combination with a titanium aquarium heater (Finnex TH Series 300w) and a recirculating water pump (Rio 1100+). All tanks started at a daily "ambient" range of $24.5-26^{\circ} \mathrm{C}$ ("day 0"). High temperature tanks were ramped $1^{\circ} \mathrm{C}$ per

194 day for 6 days, reaching a maximum of $32^{\circ} \mathrm{C}(\mathrm{MMM}+4)$, and held at this temperature profile for

195 the remainder of the experiment (Fig. S5). Ambient temperatures increased over the course of the 196 experiment due to warming weather, but never overlapped with the high temperature treatment. 197 Apex temperature probe measurements were verified using a Traceable Certified Thermometer 198 (VWR). On days 3 and 6 of the experiment corals were randomly shuffled within each tank. 199 Coral skeletal accretion, photosynthesis and respiration rates for each fragment were determined 200 at the beginning and end of the experiment as described below, with incubations at the respective 
201 treatment temperatures. Each run included fragments from multiple experimental tanks, and

202 ambient and high temperature treatments were measured in alternating incubations.

203 Photochemical efficiency (Fv/Fm) of the Symbiodiniaceae was assessed daily as described

204 below.

205

\section{Coral fitness response}

Survival and growth: Survival was monitored weekly in the field beginning at 6 weeks post-transplantation and dead fragments were removed. Coral growth was determined for a subset of fragments using two methods: 1) skeletal accretion was determined using the buoyant

210 weight technique (Davies 1989), and 2) linear extension was determined from photographs taken

211 at a fixed distance that included a ruler and the change in the maximum axial length of each

212 fragment as quantified in ImageJ relative to the standard. Initial size measures were taken for 10

213 fragments per parent per transplant treatment $(\mathrm{N}=800)$ immediately following transplantation and

214 again following 3 months (November 2016), at which point half were sacrificially sampled (see

215 below). The remaining half were returned to the field and assessed again after 6 months of

216 transplantation ( $\mathrm{N}=400$; February 2017).

Reproductive output: Reproductive output of M. capitata, a broadcast spawning

219 simultaneous hermaphrodite (Padilla-Gamiño and Gates 2012), was quantified after 9-11 months

220 of transplantation during the spawning season (May - July 2017). This transplantation period

221 encompassed the entire reproductive development of this species (Padilla-Gamiño et al. 2014),

222 from the start of gametogenesis in late summer of 2016 through its culmination during spawning

223 the following year. Corals were collected from the reef three days prior to the new moon, placed

224 into flow-through seawater tanks under natural light (50\% shade) at the Hawai' $\mathrm{i}$ Institute of

225 Marine Biology, and monitored in individual containers for five nights beginning on the night of

226 the new moon. Total reproductive output was determined by measuring the cumulative volume

227 of egg-sperm bundles released from each individual across all nights in the months of June, July,

228 and August. Reproductive output was normalized to planar surface area of live coral tissue

229 measured from overhead photographs of each colony using ImageJ. The number of eggs per

230 bundle was determined from five individual bundles per colony as described in (Padilla-Gamiño 
231 et al. 2014). Efforts to quantify reproductive output for $P$. compressa, a gonochoric broadcast

232 spawner (Neves 2000), were unsuccessful.

233

234

235

236

237

238

239

240

241

242

243

244

245

246

247

248

249

250

251

252

253

254

255

256

257

258

259

260

261

Fitness score calculation: The fitness of coral transplants, defined as the relative contribution of individuals to the next generation, is dependent upon their ability to survive and reproduce in their new environment. In colonial organisms like corals, reproductive output is positively correlated with coral size (Hall and Hughes 1996), making growth an important metric for predicting coral fitness. We therefore developed a cumulative metric of coral fitness (i.e. fitness score) that compiled coral survival, growth (skeletal mass), and for M. capitata only, reproductive success. The proportion of individual fragments from each genet and history that survived at 6 months was multiplied by their respective growth (represented as the total change in skeletal mass across the 6 months), and for M. capitata only, by the proportion of genets from each history that successfully reproduced following transplantation.

Local specialization calculation: Local specialization (S) was calculated as the difference in fitness (W) between the home and transplanted environment for each genet, divided by the mean fitness of all corals of that species at that transplant site, regardless of origin (following (Hereford et al. 2009; Kenkel et al. 2015). Positive values indicate native genets perform better than transplanted corals; while negative values indicate genets perform better when not at their native reef (i.e., cross-transplants).

$$
S_{\text {genet } x}=\left(W_{\text {origin }}-W_{\text {transplanted }}\right) / \underline{W}_{\text {all at transplanted site }}
$$

\section{Coral metabolic traits}

Oxygen Flux: Photosynthesis and light enhanced dark respiration (LEDR) rates were quantified after 3 and 6 months of transplantation $(\mathrm{N}=400$ per time point: 5 fragments per parent per site; see results for actual totals after mortality). Corals were brought in from the field, placed in flow-through seawater tables, cleaned of any fouling organisms, and assessed within 8-hours of collection. Each coral was placed into a $250 \mathrm{~mL}$ respirometry chamber filled with ambient seawater and sealed. One control chamber (seawater only) was run alongside each round of coral incubations. Corals were maintained at constant ambient temperature $\left(\mathrm{T} 3: 24^{\circ} \mathrm{C} ; \mathrm{T} 6: 23.5^{\circ} \mathrm{C}\right)$ using a water jacket, and the water within each chamber was mixed with a magnetic stir bar. 
262 Temperature and dissolved oxygen concentrations were measured simultaneously using a Pt100

263 temperature probe and PSt7 oxygen optode (Presens), respectively, which were inserted through

264 ports in the lid of each chamber. Data were recorded once per second via an OXY-10 ST

265 (Presens). Optodes were calibrated with a $0 \%$ oxygen solution $\left(10 \mathrm{mg} \mathrm{ml}^{-1} \mathrm{NaSO}_{3}\right)$ and $100 \%$ air

266 saturated seawater. Rates of photosynthesis were measured under $700 \mu \mathrm{mol} \mathrm{m}{ }^{-2} \mathrm{~s}^{-1}$ light

267 (equivalent to midday daytime light levels on the reefs; Fig. S1) until a steady rate was observed

268 for at least 10 minutes for all corals. At this point, the lights were turned off and light enhanced

269 dark respiration (LEDR) rates were determined until a steady slope was obtained for at least 10

270 minutes. The amount of oxygen released or consumed over time was calculated by multiplying

271 by the oxygen concentrations with the volume of water (volume of the chamber less the volume

272 of the coral). Coral volumes were calculated from the mass of each coral: Volume $=$

273 mass/Density; skeletal density was empirically determined (see Supplemental Methods). The rate

274 of oxygen evolution was determined from a linear regression and rates were corrected for blank

275 chamber rates and normalized to coral surface area.

Photochemical activity: Dark adapted photochemical efficiency (Fv/Fm) was assessed

278 after 1.5, 3, and 4.5 months post-transplantation using PAM fluorometry. Corals (10 fragments

279 per parent per site; 800 total) were brought in from the field in the late afternoon and kept in

280 flow-through seawater tables under natural light (50\% shade). Corals were dark-adapted for at

281 least 30 minutes following sunset, and photochemical efficiency of photosystem II (Fv/Fm) was

282 measured using a Dive-PAM (Walz GmBH). Corals were returned to the field the following

283 morning.

Heterotrophic activity: Coral heterotrophic activity was quantified for a subset of the above corals (one per parent: 10 per history per species; $\mathrm{N}=80$ ) at 3 and 6-months post-

287 transplantation (modified from Towle et al. 2015). Coral fragments were isolated in an indoor 288 tank in $1 \mu \mathrm{m}$ filtered seawater (FSW) for a 6-hour heterotrophic deprivation period the same day 289 of collection from the field. One hour after sunset, corals were placed in $220 \mathrm{~mL}$ chambers in 1 $290 \mu \mathrm{m}$ FSW with magnetic stirring. After a 30-minute acclimation period, a natural assemblage of 291 plankton (including copepods, zoea, and phytoplankton) were added to each chamber (3,000 292 plankters $\mathrm{L}^{-1}$ ) for 60-minutes after sunset (Levas et al. 2016). Triplicate $1 \mathrm{~mL}$ water samples 
293 were collected from each chamber after 0, 30, and 60-minutes, and the number of plankters was

294 immediately counted under a dissecting microscope. Chambers without corals were used to

295 calculate background rates of prey depletion in the absence of coral feeding $(\mathrm{N}=4)$. Feeding rate

296 was calculated as the decrease in total number of plankters corrected for blank chamber rates and

297 normalized to coral surface area.

298

299

300

301

302

303

304

305

306

307

308

309

310

311

312

313

314

315

316

317

318

319

320

321

322

323

Biomass: Coral fragments were flash-frozen in liquid nitrogen following assessment of autotrophic or heterotrophic activity, and stored at $-80^{\circ} \mathrm{C}$. Tissue was removed from the skeleton using an airbrush with $0.2 \mu \mathrm{m}$ filtered seawater (FSW). The resulting homogenate was dried at $60^{\circ} \mathrm{C}$ to constant weight, then burned at $400^{\circ} \mathrm{C}$ for 4 hours. Biomass, defined here as ash free dry weight (AFDW), was calculated as the difference between the dry weight and the ash weight.

Lipids: Coral tissue total lipid content was quantified gravimetrically (modified from Wall et al. 2019) by extracting lipids from coral tissue slurries in 2:1 chloroform:methanol with $0.88 \% \mathrm{KCl}$ and $100 \%$ chloroform washing. Lipids were filtered onto pre-combusted $\left(450^{\circ} \mathrm{C}, 6 \mathrm{~h}\right)$ $\mathrm{GF} / \mathrm{F}$ filters, dried at $60^{\circ} \mathrm{C}(10-12 \mathrm{~h})$ followed by combustion at $450^{\circ} \mathrm{C}(6 \mathrm{~h})$. The remaining slurry (non-lipid fraction) was used to quantify biomass by AFDW as described above. Lipid and biomass fractions were weighed before and after combustion to the nearest $0.0001 \mathrm{~g}$. Lipids were calculated as a proportion of total tissue biomass (lipids $(\mathrm{g})+$ biomass $(\mathrm{g})$ ).

Normalization: Coral skeletons were soaked in $10 \%$ bleach overnight to remove organic matter, dried to constant weight at $60^{\circ} \mathrm{C}$, and skeletal surface area was determined by the wax dipping method (Veal et al. 2010). These values were used for normalization of autotrophic and heterotrophic activity.

\section{Statistical analysis}

Statistical analysis of coral response to transplantation were conducted in R Statistical Programming (R Core Team 2017). Univariate analyses were performed using a linear mixed effect model approach in the lme4 (Bates et al. 2015) and glmmADMB (Skaug et al. 2016) packages. Proportion survivorship was analyzed by a beta regression in the betareg package (Cribari-Neto and Zeileis 2010). Fixed effects (origin, destination, species) and random 
324 intercepts (genotype, rack) of models for each coral response are described in detail in Table S1.

325 For all models, assumption of residual normality was assessed using quantile-quantile plots and

326 homogeneity of variance of residuals was assessed using the Levene's test in the car package

327 (Fox and Weisberg 2018). Transformations were determined by AIC model selection.

328 Heterotrophic feeding and buoyant weight data were square root transformed and biomass and

329 dark-adapted yield data were log transformed to meet assumptions of analyses, but data are

330 plotted as untransformed values. Significance testing was completed using Type III ANOVA

331 sum of squares tests in the lmerTest package (Kuznetsova et al. 2017) and car packages (Fox and

332 Weisberg 2018). Principal component analysis (PCA) was used to determine the percent

333 variance explained by seven physiological variables (biomass, calcification, linear extension,

334 gross photosynthetic rate, LEDR, P:R, and survival) in the separation of the transplant groups,

335 using data from all genets, and to quantify the extent of plasticity exhibited by each origin

336 population. PCA was conducted on the scaled and centered data using the prcomp function in the

337 Vegan package (Oksanen et al. 2007). Given that the first two PCs explained the majority of the

338 variance, phenotypic plasticity of each genet was calculated as the PCA distance between that

339 genet's native vs. cross-transplanted phenotype in two-dimensional trait space (i.e. PC1 vs. PC2),

340 which accounts for correlations among traits (as in (Abbott et al. 2018) and is reported as

341 plasticity. Differences in plasticity were tested using a two-way ANOVA with the factors of

342 Species and Origin.

Results

346 Distinct physicochemical dynamics characterized each reef. Temperature dynamics did not

347 differ significantly between the two patch reefs, with mean temperatures of $25.23 \pm 1.55^{\circ} \mathrm{C}$ at the

348 Outer Lagoon reef and $25.14 \pm 1.56^{\circ} \mathrm{C}$ at the Inner Lagoon reef across the six-month

349 transplantation period, and a corresponding mean diel range of $0.50 \pm 0.16^{\circ} \mathrm{C}$ vs. $0.52 \pm 0.16^{\circ} \mathrm{C}$,

350 respectively (Fig. 2A-B; Table 1). Mean pH and dissolved oxygen (DO) were also similar

351 between the two reefs (Fig. 2, Table 1), as were light levels (Fig. S1; Table 1). Diel fluctuations

352 in $\mathrm{pH}$ and DO were significantly greater at the Outer Lagoon than the Inner Lagoon reef (Fig. 2),

353 with the daily $\mathrm{pH}$ amplitude 2.92-fold higher at the Outer Lagoon reef than the Inner Lagoon reef

354 (0.111 pH units day ${ }^{-1}$ vs. $0.038 \mathrm{pH}$ units day ${ }^{-1}$, respectively) and 2.68-fold higher for DO at the 
355 Outer Lagoon reef than the Inner Lagoon reef $\left(73.9 \mu \mathrm{M}_{\text {day }^{-1}}\right.$ vs. $27.6 \mu \mathrm{M}$ day $^{-1}$, respectively;

356 Table 1). Sedimentation rates were 8.27-fold higher at the Outer Lagoon $\left(0.324 \pm 0.066 \mathrm{~g} \mathrm{day}^{-1}\right)$

357 than the Inner Lagoon reef $\left(0.039 \pm 0.003 \mathrm{~g} \mathrm{day}^{-1}\right.$; Wilcoxon rank sum test, $\mathrm{p}<0.0001$; Table 1$)$.

358 Relative flow rates were also $\sim 2$-fold higher at the Outer Lagoon reef (t-test, $\mathrm{p}<0.0001$; Table 1).

359 In contrast, diel fluctuations in salinity were lower at the Outer Lagoon than the Inner Lagoon

360 reef (Fig. 2E-F, Table 1).

Coral acute heat stress response was unaffected by transplantation. At the initiation of the

363 acute heat stress experiment (maximum daily temperature of $27^{\circ} \mathrm{C}$ across all treatments; Fig. S8),

364 there were no significant differences in performance metrics (i.e., LEDR, Fv/Fm, and gross

365 photosynthesis) between species, treatments, origins, or destinations (Fig. S9). At the end of the

366 10-day heat stress, the heat treatment reached a daily maximum of $32^{\circ} \mathrm{C}$ (maximum monthly

367 mean $\left.[\mathrm{MMM}]+4^{\circ} \mathrm{C}\right)$, while the ambient treatment reached a daily maximum of $28^{\circ} \mathrm{C}$ (Fig. S8).

368 At this point, linear mixed models (Table S21) indicated that treatment was a significant factor

369 across all parameters examined, with corals in the heat treatment exhibiting declines in

370 photochemical yield (Figure 3A; Table S22), metabolic rates (Figure 3B,C; Table S23), and

371 calcification rates (Figure 3D, Table S24). For corals in the heat treatment, origin was not a

372 significant factor for any of the metrics examined (Tables S22-24), indicating that there was no

373 change in bleaching resistance six months following transplantation to a novel environment. This

374 was true for cross-transplanted corals relative to their performance at their native reef (i.e.

375 between destinations), and for cross-transplanted corals relative to native corals within each reef

376 (i.e. within destinations; Figure 3). Species was also a significant factor for photochemical yield

377 (Table S22), photosynthesis (Table S23), and calcification rates (Table S24), but not respiration

378 (LEDR) rates (Table S23). Overall, P. compressa showed the greatest declines in performance

379 metrics in response to heat stress, with declines in photochemical yield, metabolism, and

380 calcification exceeding those of $M$. capitata (Fig. 3A-D). In contrast to the pattern seen in the

381 field, coral performance was not influenced by destination at the end of the acute heat stress

382 experiment (Table S22-24). There was however a significant 3-way interaction between

383 destination, species and treatment for calcification (Table S24), driven by lower calcification of

384 Outer Lagoon natives of $P$. compressa at ambient conditions relative to cross-transplants under

385 ambient conditions acclimatized to that site (Fig. 3D). 
Coral fitness differed between reefs but no evidence of site specialization. Overall, corals at the

Outer Lagoon reef showed significantly higher fitness scores than corals at the Inner Lagoon reef. There were, however, no differences in fitness between native and cross-transplanted corals at the Outer Lagoon (Figure 4A,B, Table S19-20). In contrast, at the Inner Lagoon reef, cross-

391 transplants of M. capitata displayed higher fitness than native corals, but only when accounting 392 for differences in reproductive success (Figure 4A, Table 19-20). Absence of reproductive data 393 from the $P$. compressa fitness score calculation implicitly assumes $100 \%$ reproductive success,

394 so these values could only decrease with the inclusion of additional data. Sequencing of 395 microsatellite markers confirmed that the $M$. capitata colonies sampled were not clones (Table 396 S25), however genotyping of $P$. compressa was unsuccessful. Despite lack of molecular 397 confirmation for $P$. compressa, it is unlikely that the individuals used in this study were clones 398 because of distance apart on the reef and low levels of clonality within the lagoon (Locatelli and

399 Drew, n.d.). Local specialization of each genet was calculated by considering the relative fitness

400 of that genet in its native vs. cross-transplanted environment. In general, corals exhibited positive 401 specialization values at the Outer Lagoon reef, whereas corals native to the Inner Lagoon reef 402 showed negative specialization values (Figure 4B), indicating corals performed better at the 403 Outer Lagoon reef even when it was not their native environment. The only exceptions were one 404 genet of $M$. capitata native to the Outer Lagoon, which had a negative local specialization score, 405 indicating it had higher fitness when cross-transplanted to the Inner Lagoon, and one genet of $P$. compressa native to the Inner Lagoon that had a positive local specialization score and was thus

407 the only genet of either species native to the Inner Lagoon that had higher fitness at its native 408 reef (Figure 4B).

411 differences in coral phenotypes were observed between destinations and species after both three 412 and six months following transplantation ( $\mathrm{p}=0.001$; PERMANOVA; Fig. 5A,B). There was also 413 a significant interaction between species and destination at both time points $(\mathrm{p}=0.003$ for T3 and $414 \mathrm{p}=0.001$ for T6; PERMANOVA). In contrast, origin was not a significant factor at either time 415 point, indicating that both species had acclimatized to their destination reef as early as three 416 months following transplantation. Genotype plasticity, quantified as the PC distance between 
417 each genet's native vs. cross-transplanted phenotype, did not differ between the two origin

418 populations for either species. Plasticity did differ between species, with $P$. compressa exhibiting

419 higher phenotypic plasticity than M. capitata at both T3 $(\mathrm{p}<0.0004)$ and T6 (p=0.017) (Fig.

$4205 \mathrm{C}, 5 \mathrm{~F})$. The traits contributing most strongly to differences between destinations included

421 metabolic rates and growth, which were higher at the Outer Lagoon reef after three months,

422 whereas biomass and survival were higher at the Inner Lagoon reef (Fig. 5A). After six months

423 post-transplantation, all traits were higher at the Outer Lagoon reef. Comparing species, $P$.

424 compressa had higher biomass, $\mathrm{P}$, and $\mathrm{R}$, while $M$. capitata exhibited higher survival, growth,

425 and P:R (Fig. 5D).

Physiological responses following transplantation.

428 Metabolic traits: Both species had greater biomass at the Outer Lagoon reef than 429 conspecifics at the Inner Lagoon reef after three months, and P. compressa had greater biomass 430 than $M$. capitata across both reefs regardless of origin (Figure 6A, Table S2-3). Lipid content 431 also differed between species and destinations but not origin, with corals at the Outer Lagoon 432 having lower lipid content and $P$. compressa tissues containing lower proportions of lipids than 433 M. capitata (Figure S3, Table S4-5). All corals consumed plankton through heterotrophic 434 feeding activity, depleting the prey population at a rate ranging from 7.5 to 27 plankters $\mathrm{cm}^{-2} \mathrm{~h}^{-1}$. 435 P. compressa also had higher feeding rates at the Inner Lagoon reef relative to the Outer Lagoon 436 reef at six months (Figure S4B); M. capitata feeding rates were also higher at the Inner Lagoon 437 reef, but only at the three-month time point (Figure S4A, Table S6-7). P. compressa had higher 438 feeding rates than M. capitata after six, but not three months of transplantation (Figure S4A-B).

Autotrophic activity was measured by assessing photochemical efficiency and

441 between origins or destinations, but was higher for M. capitata than P. compressa after 1.5

442 months of transplantation (Figure S5A, Table S8-9). After three months, both species and

443 destination were significant factors, but at 4.5 months none of the factors were significant

444 (Figure S5B-C, Table S8-9). Gross photosynthesis rates also differed between destinations and

445 species after three months of transplantation, where they were higher overall at the Outer Lagoon 446 reef and higher for P. compressa than M. capitata within each reef (Figure S2B, Table S10-11).

447 In contrast, six months after transplantation there was a significant interaction between origin 
448 and destination, as corals of both species originating from the Outer Lagoon reef showed a

449 decline in photosynthesis rates at the Inner Lagoon reef relative to the Outer Lagoon reef

450 whereas corals originating from the Inner Lagoon reef showed no difference in photosynthesis

451 rates between their native Inner Lagoon vs. the Outer lagoon reef (Figure 6B, Table S10-11).

452 Respiration rates also differed between species and destinations after three months of

453 transplantation, and similar to photosynthesis were higher at the Outer Lagoon reef than the

454 Inner Lagoon reef and higher for $P$. compressa than M. capitata (Figure S2C, Table S10,12).

455 After six months of transplantation, similar again to photosynthesis rates, species and destination

456 were no longer significant factors for respiration, but there was a significant interaction between

457 origin and destination (Figure $6 \mathrm{C}$, Table $\mathrm{S} 10$ ). The relative ratios of photosynthesis to respiration

458 (P:R) were not different between species, destination, or origin after three months of

459 transplantation (Figure S2D, Table S10). In contrast, after six months of transplantation, species

460 and destination were significant factors, and there was a significant interaction between the two

461 where P:R was higher at the Outer Lagoon for $P$. compressa but lower at the Outer Lagoon for

462 M. capitata relative to the Inner Lagoon (Figure 6D, Table S10). In addition, M. capitata had

463 higher P:R than P. compressa at the Inner Lagoon, which was driven by the relatively high

464 respiration rates of $P$. compressa vs. $M$. capitata at that site that balanced out the higher

465 photosynthesis rates of $P$. compressa at that site (Figure 6D, Table S13).

466

Survival, growth and reproduction: Species was the only significant factor affecting survival at both time points, which was higher for M. capitata than P. compressa at both reefs

469 (Figure 6E, Figure S2E, Tables S14-15). Destination was the only significant factor affecting 470 calcification, which after three months was higher for both species at the Outer Lagoon reef 471 relative to the Inner Lagoon reef regardless of origin (Figure S2F, Table S16-17). However, 472 these differences were no longer significant after six months (Figure 6F). Linear extension did 473 not differ between species, origin or destination at either time point (Figure 6G, Figure S2G, 474 Tables S16,S18). Reproductive success, quantified as the proportion of $M$. capitata genets from 475 each transplant group that successfully spawned, was significantly affected by both origin and 476 destination (Table S14). Reproductive success of $M$. capitata at the Outer Lagoon reef was 477 higher than at the Inner Lagoon reef and did not differ between origins (Figure 6H), whereas at 478 the Inner Lagoon reef native $M$. capitata had lower reproductive success $(50 \%)$ than cross- 
transplants $(90 \%$; Figure $6 \mathrm{H})$. This is the only metric examined in this study where origin alone was a significant factor. Reproductive output was not significantly different between origin or destination (mean $0.018 \pm 0.019 \mathrm{~mL} \mathrm{~cm}^{-2}$ live tissue; Figure S6). Cross-transplants at the Inner

482 Lagoon reef (i.e. introduced from the Outer Lagoon reef) showed a strong positive relationship between growth and reproduction $\left(\mathrm{p}<0.005, \mathrm{r}^{2}=0.700\right.$; Figure $\left.\mathrm{S} 7\right)$. In contrast, natives at the

484 Inner Lagoon showed no relationship between growth and reproduction. Likewise, at the Outer

485 Lagoon reef there was no relationship between growth and reproduction for either native or cross-transplanted corals, indicating that there were no negative tradeoffs between growth and reproduction.

\section{Discussion}

Fitness consequences of coral acclimatization to novel environments.

Science-based restoration is key to the success of reefs restored through human intervention. Here, we show transplantation of bleaching-resistant corals to a novel environment in situ did not alter their heat stress response, despite transplants exhibiting high levels of phenotypic plasticity for other traits. Because bleaching-resistant individuals have lower mortality (Matsuda et al. 2020) and higher reproductive success (Fisch et al. 2019; Ward et al.

497 2000; Howells et al. 2016) than bleaching-sensitive conspecifics following a bleaching event,

498 they have a clear selective advantage during and in the years following these events. Harnessing these natural advantages by propagating bleaching-resistant individuals is a promising approach to increase the abundance of corals with these traits, and could potentially increase the bleaching resistance of a reef using native (i.e. endemic, local) coral stocks. Furthermore, because bleaching resistance in these species can persist through multiple bleaching events (e.g. 2014 vs. 2015, Ritson-Williams 2020), these individuals are likely to retain their thermal tolerance across

504 longer time periods than the current study (6-11 months). Montipora capitata and P. compressa 505 represent divergent lineages of two globally distributed coral genera, suggesting these patterns

506 could be common to other species. Taken together, these results indicate that bleaching 507 resistance is both consistent through time and unaffected by transplantation to a novel 508 environment, and is thus a useful trait for selecting corals for propagation and outplanting to 509 enhance resistance of coral populations to climate change. 
511 must be assessed and understood. For instance, bleaching-resistant individuals introduced to a

512 new site during non-bleaching years should persist without substantially lowering the fitness of

513 the recipient population even in the absence of a heatwave. Encouragingly, our results

514 demonstrate that there were no negative effects on fitness of recipient populations when new

515 genets were introduced, as the recipient population's fitness either increased (at the less-

516 favorable site) or stayed the same (at the favorable site) following introduction of bleaching

517 resistant corals during a non-bleaching year. The duration of the observed enhanced fitness,

518 which lasted at least 11 months, remains unknown, as they could be the result of a temporary

519 carryover of the energetic benefits of having originated from a more favorable reef environment.

520 However, even if this carryover is transient, the long-term fitness effects of their introduction are

521 likely net positive due to the transplants' bleaching resistance, as discussed above. These results

522 are a necessary first step to validate this trait-guided approach to reef restoration. The next

523 important step is to determine if these traits can persist and spread throughout a recipient

524 population, which requires traits to be both heritable and introduced in sufficient abundance.

525 Initial studies indicate that stress-resistant corals must be introduced in numbers equivalent to at

526 least $2-5 \%$ of the population per year for several decades in order to achieve adaptive gains in

527 heat tolerance that can keep pace with climate change (Bay et al. 2017). As such, work is needed

528 to scale up these approaches if they are to have a meaningful impact on coral reef resistance to

529 ocean warming.

Acclimatization via physiological plasticity did not lead to negative tradeoffs

532 Acclimatization via plasticity can lead to negative trade-offs, where improvements or

533 maintenance of one trait (e.g. growth) come at the expense of another (e.g. reproduction),

534 making identification of possible trade-offs important both for understanding coral biology and

535 for informing trait-guided restoration. Here, transplantation revealed high levels of phenotypic

536 plasticity across a range of traits including metabolism, feeding, growth, and reproduction.

537 Regardless of the directional change, acclimatization via plasticity did not result in negative

538 tradeoffs for any of the traits examined. Critically, plasticity in growth and metabolism did not

539 alter coral heat stress responses for either species, even though $P$. compressa exhibited greater

540 plasticity than M. capitata. Also important was the lack of tradeoffs between growth, 
541 reproduction, and survival. For example, $M$. capitata genets that increased growth rates

542 following transplantation also exhibited increased reproductive success with no differences in

543 survivorship. Conversely, genets with the largest declines in growth following transplantation

544 also had lower reproductive success, indicating that a lack of investment in growth was not

545 compensated for by increased investments in reproduction. While this study cannot speak to

546 effects of transplantation on $P$. compressa reproductive tradeoffs, it appears that corals at a

547 favorable site performed better across all performance metrics, with none coming at the cost of

548 another. These results are consistent with data from other reef systems that found absence of

549 trade-offs with bleaching and reproduction (Lenz 2020) and resistance to multiple stressors

550 (Wright et al. 2019), and holds promise that these bleaching-resistant genets may also withstand

551 additional stressors.

552 The magnitude of phenotypic plasticity was greater for P. compressa than M. capitata,

553 aligning with recent work showing that $M$. capitata calcification is less sensitive than $P$.

554 compressa to differences in environmental conditions (Barnhill et al. 2020). The differences

555 observed here may be due to differential responses to the lower flow regime at the Inner Lagoon

556 reef, which can lead to greater accumulation of metabolic wastes immediately surrounding the

557 coral surface and could have depressed growth and metabolism (Mass et al. 2010). Porites

558 compressa may be more sensitive to metabolic inhibition under low flow because of its higher

559 biomass (i.e. thicker tissue) and higher respiration rates than M. capitata. Alternatively or in

560 addition, differences in plasticity could have been due in part to morphological plasticity (Todd

561 2008), as M. capitata grew longer, thinner branches at the Inner Lagoon reef than the Outer

562 Lagoon reef, which could thin boundary layers and increase diffusive exchange between the

563 tissues and surrounding seawater (Patterson 1992). Finally, differences in mixotrophy could help

564 explain these responses, as heterotrophic feeding can sustain metabolic demands during

565 environmental changes (Fox et al. 2018), and could have influenced metabolic rates and growth.

567 Genotype-environment effects

568 Both species exhibited variation between genets in the magnitude and direction of their

569 physiological response to each environment. Despite consistently higher mean coral performance

570 at the Outer Lagoon reef, in many cases these differences in performance between the two reefs

571 were not significant due to a strong genotype-environment (GxE) effect, where some individual 
572 genets showed higher performance at the Inner Lagoon for some traits. Such differences driven

573 by GxE effects within this cohort of bleaching resistant corals create critical challenges in the

574 selection of individuals with desired climate change resistant traits for coral reef restoration

575 efforts, while also accounting for future performance in other important traits. Growth in

576 particular showed a strong GxE effect, and our findings align with recent work cautioning

577 against using growth alone as a predictive trait for future coral performance as it can vary

578 between seasons (Edmunds and Putnam 2020; Edmunds 2017) and heat tolerance in a stressful

579 environment does not correspond with rapid growth in a less stressful environment (Bay and

580 Palumbi 2017). In summary, this study indicates that bleaching resistance is not plastic in these

581 species and is thus an informative trait for predicting future coral performance. Furthermore,

582 these results argue for using genetically diverse 'planting stock' to account for the wide range of

583 expressed phenotypes in different reef environments (Drury et al. 2017).

Biologically guided strategies for coral reef restoration

There is mounting evidence that 'natural' dispersal of heat tolerant genets and the generation times required for adaptation to increase heat tolerance of coral populations cannot

588 keep pace with ocean warming (Quigley et al. 2019). The rapid decline of coral reef habitats accentuates the need for human interventions in management and restoration, such as coral

590 propagation and outplanting. Here we show that bleaching resistance in corals was maintained

591 following introduction to novel environments. Bleaching resistance has shown high heritability

592 in other species (Yetsko et al. 2020; Quigley et al. 2020), and consistent relative ranking of

593 individuals in a common garden setting (Morikawa and Palumbi 2019). While more work is

594 needed to determine how well bleaching resistance persists across generations, these results

595 favor active restoration for promoting climate-ready reefs as the sources of climate change

596 become properly managed. Bleaching resistant genets can be identified either during bleaching 597 events (as in this study) or standardized acute heat stress response assays (Voolstra et al. 2020).

598 Both approaches can facilitate rapid identification of bleaching resistant genets. These efforts

599 could also focus on sites with characteristics known to foster stress tolerant populations (Palumbi

600 et al. 2014). For example, local reefs with high diel variation in temperature, shallow bays with

601 lower flow and thus higher mean temperatures often harbor heat resistant individuals. One such

602 example of this is Kāne'ohe Bay, Hawai'i, where corals have higher heat and acidification 
603 tolerances than conspecifics from neighboring reefs (Coles et al. 2018; Jury and Toonen 2019;

604 Schoepf et al. 2017) due to the higher mean temps and lower $\mathrm{pH}$ of the bay relative to nearby

605 reefs (Drupp et al. 2011). Additional traits are also important when selecting individuals for

606 restoration (e.g. ocean acidification tolerance, disease resistance and genetic diversity; (Muller et

607 al. 2018) plasticity of many of these traits are not well described. Encouragingly, relative growth

608 during acidification stress is consistent in several coral species (Jury et al. 2019), and thus along

609 with bleaching resistance may be a useful selection marker for promoting climate-ready reefs via

610 active restoration.

611 Site selection for nurseries and outplanting is also an important consideration to

612 maximize restoration success. Here we found that the reef with the greatest water flow, diel

613 physicochemical variation, and distance from land resulted in higher coral growth and fitness

614 than the other reef. High flow and high variability have also been found to promote coral

615 performance in other reef systems (Sully et al. 2019; Safaie et al. 2018) and can mitigate

616 bleaching responses (Page et al. 2019), indicating that these may be generalizable characteristics

617 of high fitness and bleaching resistant coral reefs for many species, though not all (Klepac and

618 Barshis 2020). Our results highlight the importance of selecting sites that promote high coral

619 fitness for nurseries and outplant sites, as this could accelerate the successful establishment of

620 corals following outplanting. Furthermore, an in situ nursery site that promoted faster growth

621 would provide obvious logistical benefits, as it would lead to shorter residence time in the

622 nursery and yield greater coral biomass for outplanting. Assisted gene flow using climate-ready

623 genets could complement traditional conservation measures such as marine protected areas

624 (MPAs), which could provide favorable habitat for stress-resistant outplants, and in coordination

625 with less directed approaches (e.g. adaptation neworks; Webster et al. 2017), preserve genetic

626 diversity. Recruitment to the reef is another critical contributor towards coral fitness and

627 population persistence (Ritson-Williams et al. 2009), and potential for high recruitment success

628 is clearly an important factor for selecting an outplant reef. While the water quality parameters

629 discussed above that promote adult colony success also likely contribute to juvenile health post-

630 settlement, additional factors (e.g. settlement habitat, abundance of herbivores, prevalence of

631 coral disease) are critical for recruitment to the reef (Ritson-Williams et al. 2009) and should also

632 be considered when selecting outplant sites. Although sites in greatest need of restoration may

633 not be "high fitness" sites, using corals from favorable sites or nurseries may still benefit the 
634 recipient population at a 'low fitness' reef for two reasons: 1) corals from a 'high-fitness' reef

635 had higher reproductive success than native corals, likely boosting the fitness of the recipient

636 population, and 2) introduction of bleaching resistant individuals should improve the fitness of

637 that population during increasingly frequent marine heatwaves (Frölicher et al. 2018). Future

638 work is needed to determine if either of these coral traits (high fitness and bleaching resistance)

639 persists through the next spawning season or heatwave, or the next generation. Promisingly,

640 putting corals in a good site improved their reproductive success, which could be beneficial for

641 practitioners seeking to increase the genetic diversity of a recipient population (or rescue rare

642 genets from a damaged or dying site), as transplanting these corals could be beneficial for the

643 individual being moved without harming the recipient population. Thus, assisted gene flow could

644 be another strategy for restoring and maintaining genetic diversity that also increases heat

645 resistance of a population.

646 


\section{References}

681

682

683

684

685

686

687

688

689

690

691

692

693

694

695

696

Abbott, Jessica M., Katherine DuBois, Richard K. Grosberg, Susan L. Williams, and John J. Stachowicz. 2018. "Genetic Distance Predicts Trait Differentiation at the Subpopulation but Not the Individual Level in Eelgrass, Zostera Marina." Ecology and Evolution 8 (15): 7476-89.

Ainsworth, Tracy D., Scott F. Heron, Juan Carlos Ortiz, Peter J. Mumby, Alana Grech, Daisie Ogawa, C. Mark Eakin, and William Leggat. 2016. "Climate Change Disables Coral Bleaching Protection on the Great Barrier Reef." Science 352 (6283): 338-42.

Albright, Rebecca, Lilian Caldeira, Jessica Hosfelt, Lester Kwiatkowski, Jana K. Maclaren, Benjamin M. Mason, Yana Nebuchina, et al. 2016. "Reversal of Ocean Acidification Enhances Net Coral Reef Calcification." Nature 531 (7594): 362.

Andersson, Andreas J., and Dwight Gledhill. 2013. "Ocean Acidification and Coral Reefs: Effects on Breakdown, Dissolution, and Net Ecosystem Calcification." Annual Review of Marine Science 5: 321-48.

Anthony, Kenneth R. N., Kate J. Helmstedt, Line K. Bay, Pedro Fidelman, Karen E. Hussey, Petra Lundgren, David Mead, et al. 2020. "Interventions to Help Coral Reefs under Global Change-A Complex Decision Challenge." PloS One 15 (8): e0236399.

Anthony, Kenneth R. N., Paul A. Marshall, Ameer Abdulla, Roger Beeden, Chris Bergh, Ryan Black, C. Mark Eakin, et al. 2015. "Operationalizing Resilience for Adaptive Coral Reef Management under Global Environmental Change." Global Change Biology 21 (1): 48-61.

Baird, A. H., and P. A. Marshall. 2002. "Mortality, Growth and Reproduction in Scleractinian Corals Following Bleaching on the Great Barrier Reef." Marine Ecology Progress Series 237 (July): 13341.

Baker, Andrew C., Peter W. Glynn, and Bernhard Riegl. 2008. "Climate Change and Coral Reef Bleaching: An Ecological Assessment of Long-Term Impacts, Recovery Trends and Future Outlook." Estuarine, Coastal and Shelf Science 80 (4): 435-71.

Barnhill, Kelsey Archer, Nadia Jogee, Colleen Brown, Ashley McGowan, Ku'ulei Rodgers, Ian Bryceson, and Keisha Bahr. 2020. "Acclimatization Drives Differences in Reef-Building Coral Calcification Rates.” Diversity 12 (9): 347.

Bates, Douglas, Martin Mächler, Ben Bolker, and Steve Walker. 2015. "Fitting Linear Mixed-Effects Models Using lme4." Journal of Statistical Software 67 (1): 1-48.

Baums, Iliana B., Jennifer N. Boulay, Nicholas R. Polato, and Michael E. Hellberg. 2012. "No Gene Flow across the Eastern Pacific Barrier in the Reef-Building Coral Porites Lobata." Molecular Ecology 21 (22): 5418-33.

Bay, Rachael A., and Stephen R. Palumbi. 2017. "Transcriptome Predictors of Coral Survival and Growth in a Highly Variable Environment." Ecology and Evolution 7 (13): 4794-4803.

Bay, Rachael A., Noah H. Rose, Cheryl A. Logan, and Stephen R. Palumbi. 2017. "Genomic Models Predict Successful Coral Adaptation If Future Ocean Warming Rates Are Reduced." Science Advances 3 (11): e1701413.

Castillo, K. D., and B. S. T. Helmuth. 2005. "Influence of Thermal History on the Response of Montastraea Annularis to Short-Term Temperature Exposure." Marine Biology 148 (2): 261-70.

Coles, Steve L., Keisha D. Bahr, Ku'ulei S. Rodgers, Stacie L. May, Ashley E. McGowan, Anita Tsang, Josh Bumgarner, and Ji Hoon Han. 2018. "Evidence of Acclimatization or Adaptation in Hawaiian Corals to Higher Ocean Temperatures." PeerJ 6 (August): e5347.

Concepcion, Gregory T., Nicholas R. Polato, Iliana B. Baums, and Robert J. Toonen. 2010. "Development of Microsatellite Markers from Four Hawaiian Corals: Acropora Cytherea, Fungia Scutaria, Montipora Capitata and Porites Lobata." Conservation Genetics Resources. https://doi.org/10.1007/s12686-009-9118-4.

Cribari-Neto, Francisco, and Achim Zeileis. 2010. "Beta Regression inR.” Journal of Statistical Software. https://doi.org/10.18637/jss.v034.i02.

Davies, P. Spencer. 1989. "Short-Term Growth Measurements of Corals Using an Accurate Buoyant 
Weighing Technique.” Marine Biology 101 (3): 389-95.

Dickson, A. G., C. L. Sabine, and J. R. Christian. 2007. "Guide to Best Practices for Ocean CO2 Measurements." North Pacific Marine Science Organization. http://www.oceanbestpractices.net:80/handle/11329/249.

Doney, Scott C., Victoria J. Fabry, Richard A. Feely, and Joan A. Kleypas. 2009. "Ocean Acidification: The Other CO2 Problem." Annual Review of Marine Science 1: 169-92.

Doty, Maxwell. 1971. "Measurement of Water Movement in Reference to Benthic Algal Growth." Botanica Marina 14 (1): 32-35.

Drupp, Patrick, Eric Heinen De Carlo, Fred T. Mackenzie, Paul Bienfang, and Christopher L. Sabine. 2011. "Nutrient Inputs, Phytoplankton Response, and CO2 Variations in a Semi-Enclosed Subtropical Embayment, Kaneohe Bay, Hawaii." Aquatic Geochemistry 17 (4): 473-98.

Drupp, Patrick S., Eric Heinen De Carlo, Fred T. Mackenzie, Christopher L. Sabine, Richard A. Feely, and Kathryn E. Shamberger. 2013. "Comparison of CO2 Dynamics and Air-aea Gas Exchange in Differing Tropical Reef Environments." Aquatic Geochemistry 19 (5-6): 371-97.

Drury, Crawford. 2020. "Resilience in Reef-Building Corals: The Ecological and Evolutionary Importance of the Host Response to Thermal Stress." Molecular Ecology 29 (3): 448-65.

Drury, Crawford, Derek Manzello, and Diego Lirman. 2017. "Genotype and Local Environment Dynamically Influence Growth, Disturbance Response and Survivorship in the Threatened Coral, Acropora Cervicornis." PloS One 12 (3): e0174000.

Edmunds, Peter J. 2017. "Intraspecific Variation in Growth Rate Is a Poor Predictor of Fitness for Reef Corals." Ecology 98 (8): 2191-2200.

- 2018. "Implications of High Rates of Sexual Recruitment in Driving Rapid Reef Recovery in Mo'orea, French Polynesia." Scientific Reports 8 (1): 1-11.

Edmunds, Peter J., and Hollie M. Putnam. 2020. "Science-Based Approach to Using Growth Rate to Assess Coral Performance and Restoration Outcomes." Biology Letters 16 (7): 20200227.

Edmunds, P. J., and R. D. Gates. 2008. "Acclimatization in Tropical Reef Corals.” Marine Ecology Progress Series 361 (June): 307-10.

Eyre, Bradley D., Tyler Cyronak, Patrick Drupp, Eric Heinen De Carlo, Julian P. Sachs, and Andreas J. Andersson. 2018. "Coral Reefs Will Transition to Net Dissolving before End of Century." Science 359 (6378): 908-11.

Fisch, Jay, Crawford Drury, Erica K. Towle, Rivah N. Winter, and Margaret W. Miller. 2019. "Physiological and Reproductive Repercussions of Consecutive Summer Bleaching Events of the Threatened Caribbean Coral Orbicella Faveolata." Coral Reefs 38 (4): 863-76.

Fordyce, Alexander J., Tracy D. Ainsworth, Scott F. Heron, and William Leggat. 2019. "Marine Heatwave Hotspots in Coral Reef Environments: Physical Drivers, Ecophysiological Outcomes, and Impact Upon Structural Complexity." Frontiers in Marine Science. https://doi.org/10.3389/fmars.2019.00498.

Fox, John, and Sanford Weisberg. 2018. An R Companion to Applied Regression. Third Edition. Sage Publications, Inc.

Fox, Michael D., Gareth J. Williams, Maggie D. Johnson, Veronica Z. Radice, Brian J. Zgliczynski, Emily L. A. Kelly, Forest L. Rohwer, Stuart A. Sandin, and Jennifer E. Smith. 2018. "Gradients in Primary Production Predict Trophic Strategies of Mixotrophic Corals across Spatial Scales." Current Biology: CB 28 (21): 3355-63.e4.

Frölicher, Thomas L., Erich M. Fischer, and Nicolas Gruber. 2018. "Marine Heatwaves under Global Warming." Nature 560 (7718): 360-64.

Hall, V. R., and T. P. Hughes. 1996. "Reproductive Strategies of Modular Organisms: Comparative Studies of Reef- Building Corals." Ecology 77 (3): 950-63.

Hereford, Joe, Associate Editor: Elizabeth Elle, and Editor: Monica A. Geber. 2009. "A Quantitative Survey of Local Adaptation and Fitness Trade-Offs." The American Naturalist 173 (5): 579-88.

Howells, Emily J., Remi N. Ketchum, Andrew G. Bauman, Yasmine Mustafa, Kristina D. Watkins, and John A. Burt. 2016. "Species-Specific Trends in the Reproductive Output of Corals across 
Environmental Gradients and Bleaching Histories." Marine Pollution Bulletin 105 (2): 532-39. Hughes, Terry P., Kristen D. Anderson, Sean R. Connolly, Scott F. Heron, James T. Kerry, Janice M. Lough, Andrew H. Baird, et al. 2018. "Spatial and Temporal Patterns of Mass Bleaching of Corals in the Anthropocene." Science 359 (6371): 80-83.

Hughes, Terry P., James T. Kerry, Andrew H. Baird, Sean R. Connolly, Tory J. Chase, Andreas Dietzel, Tessa Hill, et al. 2019. "Global Warming Impairs Stock-recruitment Dynamics of Corals." Nature 568 (7752): 387-90.

Hughes, Terry P., James T. Kerry, Andrew H. Baird, Sean R. Connolly, Andreas Dietzel, C. Mark Eakin, Scott F. Heron, et al. 2018. "Global Warming Transforms Coral Reef Assemblages." Nature 556 (7702): 492-96.

Hughes, Terry P., James T. Kerry, Sean R. Connolly, Andrew H. Baird, C. Mark Eakin, Scott F. Heron, Andrew S. Hoey, et al. 2019. "Ecological Memory Modifies the Cumulative Impact of Recurrent Climate Extremes." Nature Climate Change 9 (1): 40-43.

Johnson, Gregory C., and John M. Lyman. 2020. "Warming Trends Increasingly Dominate Global Ocean." Nature Climate Change 10 (8): 757-61.

Jokiel, Paul L. 2004. "Temperature Stress and Coral Bleaching." In Coral Health and Disease, edited by Eugene Rosenberg and Yossi Loya, 401-25. Berlin, Heidelberg: Springer Berlin Heidelberg.

Jokiel, Paul L., and Eric K. Brown. 2004. "Global Warming, Regional Trends and Inshore Environmental Conditions Influence Coral Bleaching in Hawaii." Global Change Biology 10 (10): 1627-41.

Jokiel, Paul L., and J Morrissey. 1993. "Water Motion on Coral Reefs: Evaluation of the 'Clod Card' Technique.” Marine Ecology Progress Series 93: 175-81.

Jury, Christopher P., Mia N. Delano, and Robert J. Toonen. 2019. "High Heritability of Coral Calcification Rates and Evolutionary Potential under Ocean Acidification." Scientific Reports 9 (1): 20419.

Jury, Christopher P., and Robert J. Toonen. 2019. “Adaptive Responses and Local Stressor Mitigation Drive Coral Resilience in Warmer, More Acidic Oceans." Proceedings of the Royal Society B: Biological Sciences 286 (1902): 20190614.

Kenkel, Carly D., Albert T. Almanza, and Mikhail V. Matz. 2015. "Fine-Scale Environmental Specialization of Reef-Building Corals Might Be Limiting Reef Recovery in the Florida Keys." Ecology 96 (12): 3197-3212.

Klepac, C. N., and D. J. Barshis. 2020. "Reduced Thermal Tolerance of Massive Coral Species in a Highly Variable Environment." Proceedings. Biological Sciences / The Royal Society 287 (1933): 20201379.

Kuznetsova, Alexandra, Per B. Brockhoff, and Rune H. B. Christensen. 2017. "ImerTest Package: Tests in Linear Mixed Effects Models." Journal of Statistical Software 82 (1): 1-26.

Leggat, William P., Emma F. Camp, David J. Suggett, Scott F. Heron, Alexander J. Fordyce, Stephanie Gardner, Lachlan Deakin, et al. 2019. "Rapid Coral Decay Is Associated with Marine Heatwave Mortality Events on Reefs." Current Biology. https://doi.org/10.1016/j.cub.2019.06.077.

Lenz, Elizabeth Ann. 2020. "Identifying Opportunities for Resilience in Reef-Building Corals as Ocean Warming Continues." Edited by Ruth D. Gates. University of Hawai'i at Manoa. http://scholarspace.manoa.hawaii.edu/handle/10125/68907.

Levas, Stephen, Andréa G. Grottoli, Verena Schoepf, Matthew Aschaffenburg, Justin Baumann, James E. Bauer, and Mark E. Warner. 2016. "Can Heterotrophic Uptake of Dissolved Organic Carbon and Zooplankton Mitigate Carbon Budget Deficits in Annually Bleached Corals?" Coral Reefs 35 (2): 495-506.

Locatelli, N. S., and J. A. Drew. n.d. "Population Structure and Clonal Prevalence of Scleractinian Corals (Montipora Capitata and Porites Compressa) in Kaneohe Bay, Oahu." https://doi.org/10.1101/2019.12.11.860585.

Lowe, R. J., J. L. Falter, S. G. Monismith, and M. J. Atkinson. 2009. "Wave-Driven Circulation of a Coastal Reef-lagoon System." Journal of Physical Oceanography 39 (4): 873-93.

Loya, Y., K. Sakai, K. Yamazato, Y. Nakano, H. Sambali, and R. van Woesik. 2001. "Coral Bleaching: 
The Winners and the Losers." Ecology Letters 4 (2): 122-31.

Massaro, Rachel F. S., Eric Heinen De Carlo, Patrick S. Drupp, Fred T. Mackenzie, Stacy Maenner Jones, Katie E. Shamberger, Christopher L. Sabine, and Richard A. Feely. 2012. "Multiple Factors Driving Variability of CO2 Exchange between the Ocean and Atmosphere in a Tropical Coral Reef Environment." Aquatic Geochemistry 18 (4): 357-86.

Mass, Tali, Amatzia Genin, Uri Shavit, Mor Grinstein, and Dan Tchernov. 2010. "Flow Enhances Photosynthesis in Marine Benthic Autotrophs by Increasing the Efflux of Oxygen from the Organism to the Water." Proceedings of the National Academy of Sciences of the United States of America 107 (6): 2527-31.

Matsuda, Shayle, Ariana Huffmyer, Elizabeth A. Lenz, Jen Davidson, Joshua Hancock, Ariana Przybylowski, Teegan Innis, Ruth D. Gates, and Katie L. Barott. 2020. "Coral Bleaching Susceptibility Is Predictive of Subsequent Mortality within but Not between Coral Species." Frontiers in Ecology and Evolution 8 (178): 1-14.

McClanahan, T. R. 2004. "The Relationship between Bleaching and Mortality of Common Corals." Marine Biology 144 (6): 1239-45.

Morikawa, Megan K., and Stephen R. Palumbi. 2019. "Using Naturally Occurring Climate Resilient Corals to Construct Bleaching-Resistant Nurseries." Proceedings of the National Academy of Sciences of the United States of America 116 (21): 10586-91.

Muller, Erinn M., Erich Bartels, and Iliana B. Baums. 2018. "Bleaching Causes Loss of Disease Resistance within the Threatened Coral Species Acropora Cervicornis." eLife. September 11, 2018. https://elifesciences.org/articles/35066.

National Academies of Sciences, Medicine, and Others. 2019. A Decision Framework for Interventions to Increase the Persistence and Resilience of Coral Reefs. National Academies Press.

Neves, Elizabeth G. 2000. "Histological Analysis of Reproductive Trends of Three Porites Species from Kane'ohe Bay, Hawai'i." Pacific Science 54 (2): 195-200.

Oakley, C. A., and S. K. Davy. 2018. "Cell Biology of Coral Bleaching." In Coral Bleaching: Patterns, Processes, Causes and Consequences, edited by Madeleine J. H. van Oppen and Janice M. Lough, 189-211. Ecological Studies. Cham: Springer International Publishing.

Oksanen, Jari, Roeland Kindt, Pierre Legendre, Bob O'Hara, M. Henry H. Stevens, Maintainer Jari Oksanen, and Mass Suggests. 2007. "The Vegan Package." Community Ecology Package 10 (631637): 719.

Oliver, T. A., and S. R. Palumbi. 2011. "Do Fluctuating Temperature Environments Elevate Coral Thermal Tolerance?" Coral Reefs 30 (2): 429-40.

Padilla-Gamiño, Jacqueline L., Laetitia Hédouin, Rhian G. Waller, Derek Smith, William Truong, and Ruth D. Gates. 2014. "Sedimentation and the Reproductive Biology of the Hawaiian Reef-Building Coral Montipora Capitata." The Biological Bulletin 226 (1): 8-18.

Padilla-Gamiño, J. L., and R. D. Gates. 2012. "Spawning Dynamics in the Hawaiian Reef-Building Coral Montipora Capitata." Marine Ecology Progress Series 449 (March): 145-60.

Page, Charlotte E., William Leggat, Scott F. Heron, Severine M. Choukroun, Jon Lloyd, and Tracy D. Ainsworth. 2019. "Seeking Resistance in Coral Reef Ecosystems: The Interplay of Biophysical Factors and Bleaching Resistance under a Changing Climate: The Interplay of a Reef's Biophysical Factors Can Mitigate the Coral Bleaching Response." BioEssays: News and Reviews in Molecular, Cellular and Developmental Biology 41 (7): e1800226.

Page, Heather N., Travis A. Courtney, Eric H. De Carlo, Noah M. Howins, Irina Koester, and Andreas J. Andersson. 2018. "Spatiotemporal Variability in Seawater Carbon Chemistry for a Coral Reef Flat in Kāne'ohe Bay, Hawai'i." Limnology and Oceanography 9999: 1-22.

Palumbi, Stephen R., Daniel J. Barshis, Nikki Traylor-Knowles, and Rachael A. Bay. 2014. "Mechanisms of Reef Coral Resistance to Future Climate Change." Science 344 (6186): 895-98.

Patterson, Mark R. 1992. "A Chemical Engineering View of Cnidarian Symbioses." Integrative and Comparative Biology 32 (4): 566-82.

Putnam, Hollie M., Raphael Ritson-Williams, Jolly Ann Cruz, Jennifer M. Davidson, and Ruth D. Gates. 
2020. "Environmentally-Induced Parental or Developmental Conditioning Influences Coral Offspring Ecological Performance.” Scientific Reports 10 (1): 13664.

Quigley, Kate M., Line K. Bay, and Madeleine J. H. van Oppen. 2019. "The Active Spread of Adaptive Variation for Reef Resilience." Ecology and Evolution 9 (19): 11122-35.

. 2020. "Genome-Wide SNP Analysis Reveals an Increase in Adaptive Genetic Variation through Selective Breeding of Coral." Molecular Ecology 29 (12): 2176-88.

Raphael Ritson-Williams, Suzanne N. Arnold, Nicole D. Fogarty, Robert S. Steneck, Mark J. A. Vermeij, and Valerie J. Paul. 2009. "New Perspectives on Ecological Mechanisms Affecting Coral Recruitment on Reefs." Smithsonian Contributions to the Marine Sciences, 437-57.

R Core Team. 2017. "R: A Language and Environment for Statistical Computing." R Foundation for Statistical Computing, Vienna, Austria.

Ritson-Williams, R. And R. D. Gates. 2020. "Coral Community Resilience to Successive Years of Bleaching in Kāne'ohe Bay, Hawai'i." Coral Reefs. https://doi.org/10.1007/s00338-020-01944-4.

Safaie, Aryan, Nyssa J. Silbiger, Timothy R. McClanahan, Geno Pawlak, Daniel J. Barshis, James L. Hench, Justin S. Rogers, Gareth J. Williams, and Kristen A. Davis. 2018. "High Frequency Temperature Variability Reduces the Risk of Coral Bleaching." Nature Communications 9 (1): 1671.

Schoepf, Verena, Christopher P. Jury, Robert J. Toonen, and Malcolm T. McCulloch. 2017. "Coral Calcification Mechanisms Facilitate Adaptive Responses to Ocean Acidification.” Proc. R. Soc. B 284 (1868): 20172117.

Schoepf, Verena, Michael Stat, James L. Falter, and Malcolm T. McCulloch. 2015. "Limits to the Thermal Tolerance of Corals Adapted to a Highly Fluctuating, Naturally Extreme Temperature Environment." Scientific Reports 5 (December): 17639.

Skaug, H., D. Fournier, B. Bolker, A. Magnusson, and A. Nielsen. 2016. “Generalized Linear Mixed Models Using 'AD Model Builder.” R package version 0.8.3.3.

Storlazzi, C. D., M. E. Field, and M. H. Bothner. 2011. "The Use (and Misuse) of Sediment Traps in Coral Reef Environments: Theory, Observations, and Suggested Protocols." Coral Reefs 30 (1): 2338.

Sully, S., D. E. Burkepile, M. K. Donovan, G. Hodgson, and R. van Woesik. 2019. "A Global Analysis of Coral Bleaching over the Past Two Decades.” Nature Communications 10 (1): 1264.

Todd, Peter A. 2008. "Morphological Plasticity in Scleractinian Corals." Biological Reviews of the Cambridge Philosophical Society 83 (3): 315-37.

Towle, Erica K., Ian C. Enochs, and Chris Langdon. 2015. "Threatened Caribbean Coral Is Able to Mitigate the Adverse Effects of Ocean Acidification on Calcification by Increasing Feeding Rate." PloS One 10 (4): e0123394 doi:10.1371/journal/pone.0123394.

Van Oppen, Madeleine J. H., Ruth D. Gates, Linda L. Blackall, Neal Cantin, Leela J. Chakravarti, Wing Y. Chan, Craig Cormick, et al. 2017. "Shifting Paradigms in Restoration of the World's Coral Reefs." Global Change Biology 23 (9): 3437-48.

Van Oppen, Madeleine J. H., James K. Oliver, Hollie M. Putnam, and Ruth D. Gates. 2015. "Building Coral Reef Resilience through Assisted Evolution." Proceedings of the National Academy of Sciences of the United States of America 112 (8): 2307-13.

Veal, C. J., M. Carmi, M. Fine, and O. Hoegh-Guldberg. 2010. "Increasing the Accuracy of Surface Area Estimation Using Single Wax Dipping of Coral Fragments." Coral Reefs. https://doi.org/10.1007/s00338-010-0647-9.

Voolstra, Christian R., Carol Buitrago-López, Gabriela Perna, Anny Cárdenas, Benjamin C. C. Hume, Nils Rädecker, and Daniel J. Barshis. 2020. "Standardized Short-Term Acute Heat Stress Assays Resolve Historical Differences in Coral Thermotolerance across Microhabitat Reef Sites." Global Change Biology, June. https://doi.org/10.1111/gcb.15148.

Wall, Christopher B., Raphael Ritson-Williams, Brian N. Popp, and Ruth D. Gates. 2019. "Spatial Variation in the Biochemical and Isotopic Composition of Corals during Bleaching and Recovery." Limnology and Oceanography, 1-18.

Ward, S., P. Harrison, and O. Hoegh-Guldberg. 2000. "Coral Bleaching Reduces Reproduction of 
Scleractinian Corals and Increases Susceptibility to Future Stress." Proceedings of the 9th International Coral Reef Symposium, 6.

Webster, Michael S., Madhavi A. Colton, Emily S. Darling, Jonathan Armstrong, Malin L. Pinsky, Nancy Knowlton, and Daniel E. Schindler. 2017. "Who Should Pick the Winners of Climate Change?" Trends in Ecology \& Evolution 32 (3): 167-73.

Woesik, Robert, Peter Houk, Adelle L. Isechal, Jacques W. Idechong, Steven Victor, and Yimnang Golbuu. 2012. "Climate-Change Refugia in the Sheltered Bays of Palau: Analogs of Future Reefs." Ecology and Evolution 2 (10): 2474-84.

Wright, Rachel M., Hanaka Mera, Carly D. Kenkel, Maria Nayfa, Line K. Bay, and Mikhail V. Matz. 2019. "Positive Genetic Associations among Fitness Traits Support Evolvability of a Reef-Building Coral under Multiple Stressors." bioRxiv, March, 572321.

Yetsko, K., M. Ross, A. Bellantuono, D. Merselis, M. Rodriquez-Lanetty, and M. R. Gilg. 2020. "Genetic Differences in Thermal Tolerance among Colonies of Threatened Coral Acropora Cervicornis: Potential for Adaptation to Increasing Temperature." Marine Ecology Progress Series 646 (July): $45-68$.

\section{Acknowledgements}

This work would not have been possible without the support of volunteers in the field, and we would particularly like to thank Yanitza Grantcharska, Aileen Maldonado, Dyson Chee, and the HIMB boating and diving team led by Jason Jones. We also recognize technical help from Brian Glazer and Stanley Lio with sensor deployment.

\section{Funding}

This work was supported by the Paul G. Allen Family Foundation (to RDG), the University of Pennsylvania (KLB), and National Science Foundation awards OCE-1923743 to KLB, OCEPRF 1323822 to HMP, and Graduate Research Fellowships to ASH and EAL. 
Tables

929

Table 1. Mean values and daily amplitude (where applicable) for environmental parameters at the Inner and Outer Lagoon reefs. Asterisks denote significant differences $(\mathrm{p}<0.05)$.

\begin{tabular}{|c|c|c|c|}
\hline Mean & Inner Lagoon & Outer Lagoon & $\begin{array}{c}\text { Ratio } \\
\text { (OL:IL) }\end{array}$ \\
\hline Temperature $\left({ }^{\circ} \mathrm{C}\right)$ & $25.137 \pm 1.555$ & $25.225 \pm 1.547$ & 1.00 \\
\hline $\mathrm{pH}$ & $8.007 \pm 0.028$ & $7.983 \pm 0.049$ & $1.00^{*}$ \\
\hline Dissolved oxygen $(\mu \mathrm{M})$ & $185.8 \pm 8.3$ & $177.9 \pm 13.2$ & $0.96^{*}$ \\
\hline Salinity (psu) & $33.98 \pm 0.51$ & $34.66 \pm 0.27$ & $1.02^{*}$ \\
\hline Daily light integral $\left(\mathrm{mol} \mathrm{m}^{-2} \mathrm{~d}^{-1}\right)$ & $11.3 \pm 5.24$ & $12.3 \pm 5.53$ & 1.09 \\
\hline Sedimentation rate $\left(\mathrm{g} \mathrm{day}^{-1}\right)$ & $0.039 \pm 0.003$ & $0.324 \pm 0.066$ & $8.27^{*}$ \\
\hline Flow rate $\left(\%\right.$ dissolution $\left.\mathrm{h}^{-1}\right)$ & $1.22 \pm 0.03$ & $2.35 \pm 0.03$ & $1.92^{*}$ \\
\hline Daily Amplitude & Inner Lagoon & Outer Lagoon & $\begin{array}{l}\text { Ratio } \\
\text { (OL:IL) }\end{array}$ \\
\hline Temperature $\left({ }^{\circ} \mathrm{C}\right)$ & $0.515 \pm 0.161$ & $0.499 \pm 0.161$ & 0.97 \\
\hline $\mathrm{pH}$ & $0.038 \pm 0.013$ & $0.111 \pm 0.041$ & $2.92^{*}$ \\
\hline Dissolved oxygen $(\mu \mathrm{M})$ & $27.6 \pm 9.5$ & $73.9 \pm 28.7$ & $2.68^{*}$ \\
\hline Salinity (psu) & $0.257 \pm 0.08$ & $0.06 \pm 0.014$ & $0.23^{*}$ \\
\hline Light $\left(\mu \mathrm{mol} \mathrm{m} \mathrm{m}^{-2} \mathrm{~s}^{-1}\right)$ & $590.5 \pm 21.1$ & $597.0 \pm 29.2$ & 1.01 \\
\hline
\end{tabular}



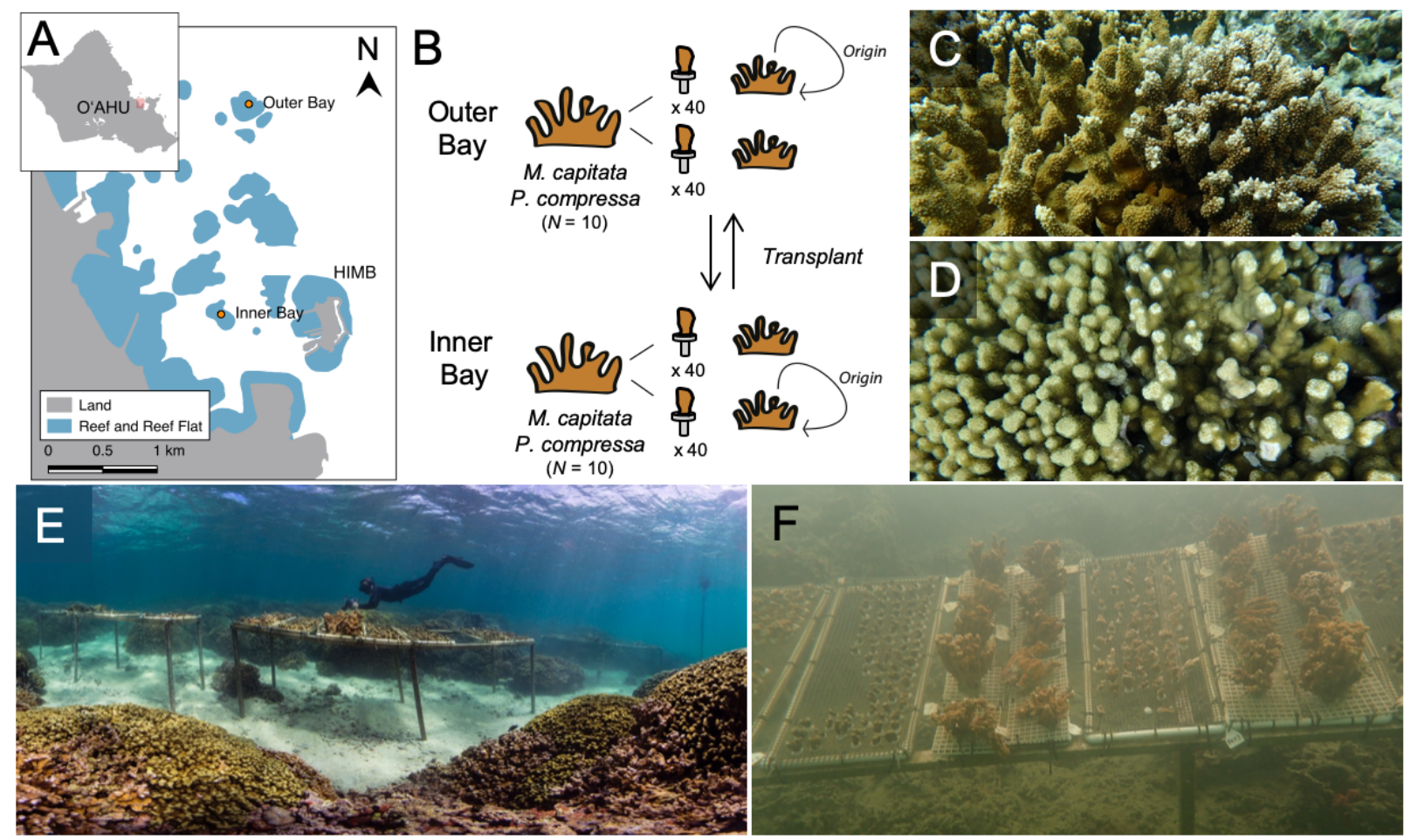

Figure 1. Overview of the experimental setup for this study. A) Map of the southern region of Kāne'ohe Bay where the study took place. Orange dots indicate the center of the Outer Lagoon and Inner Lagoon patch reefs. Inset shows the island of $\mathrm{O}^{\prime} \mathrm{ahu}$, with the red box indicating the southern region of Kāne'ohe Bay. B) Schematic of coral collection, fragmentation, and reciprocal transplantation. Representative images of the coral species used in this study for C) $M$. capitata and D) P. compressa. Images of the experimental setup at the Outer Lagoon reef (E) and the Inner Lagoon reef $(\mathrm{F})$. 

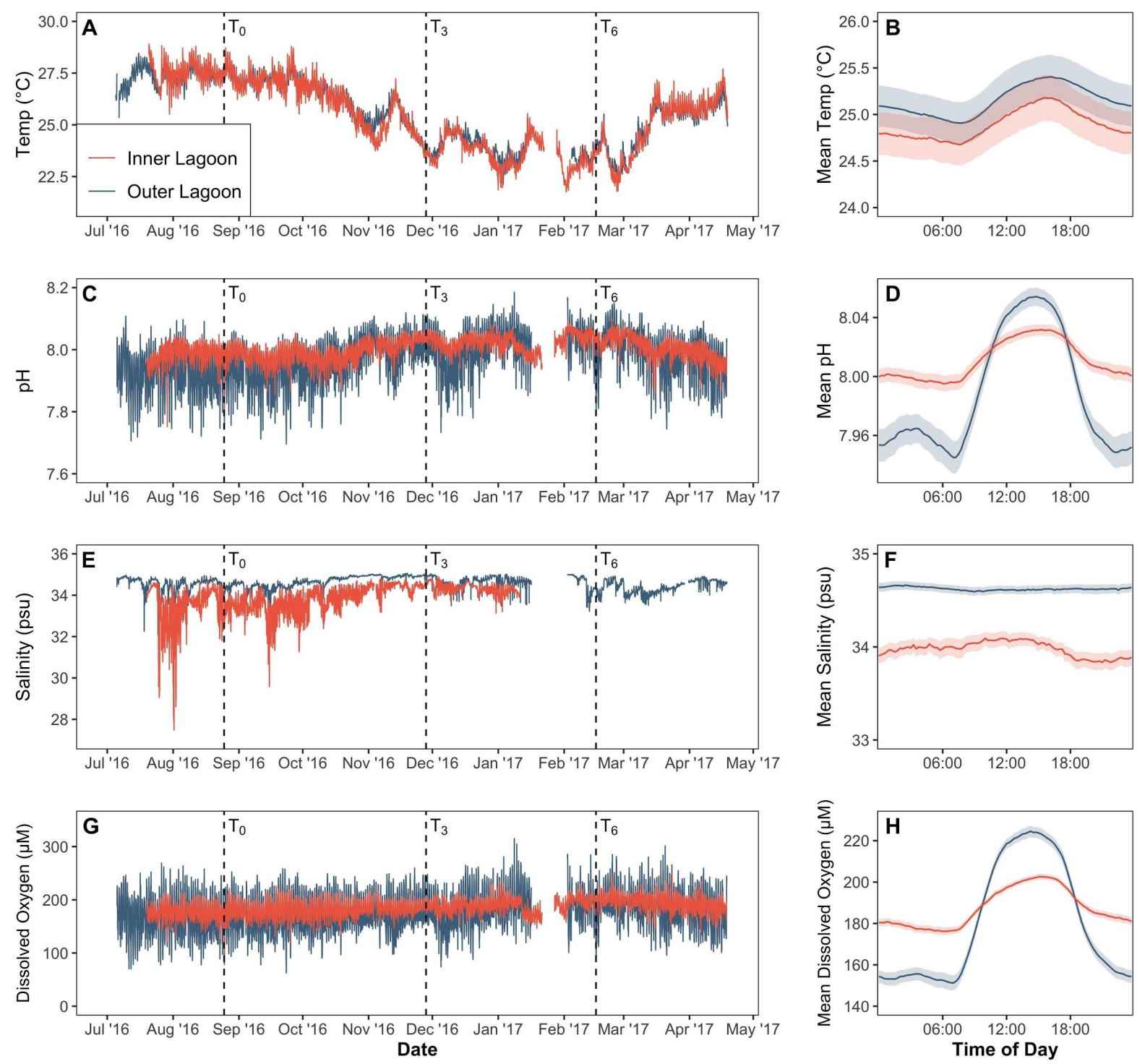

942

Figure 2. Characterization of seawater physicochemical dynamics above the reef benthos at the Inner Lagoon (orange) versus Outer Lagoon (blue) reefs. Seawater temperature time series (A) and mean diel temperature cycle (B). Seawater $\mathrm{pH}$ time series (C) and mean diel $\mathrm{pH}$ cycle (D). Salinity time series (E) and mean diel salinity cycle (F). Seawater dissolved oxygen (DO) content time series $(\mathrm{G})$ and mean diel DO cycle $(\mathrm{H})$. Vertical dashed lines indicate the initiation of the transplant $\left(\mathrm{T}_{0}\right)$ followed by sampling time points after 3 months $\left(\mathrm{T}_{3}\right)$ and 6 months $\left(\mathrm{T}_{6}\right)$ of transplantation. The mean diel cycles are shown with shading indicating $\pm 95 \%$ confidence interval. 

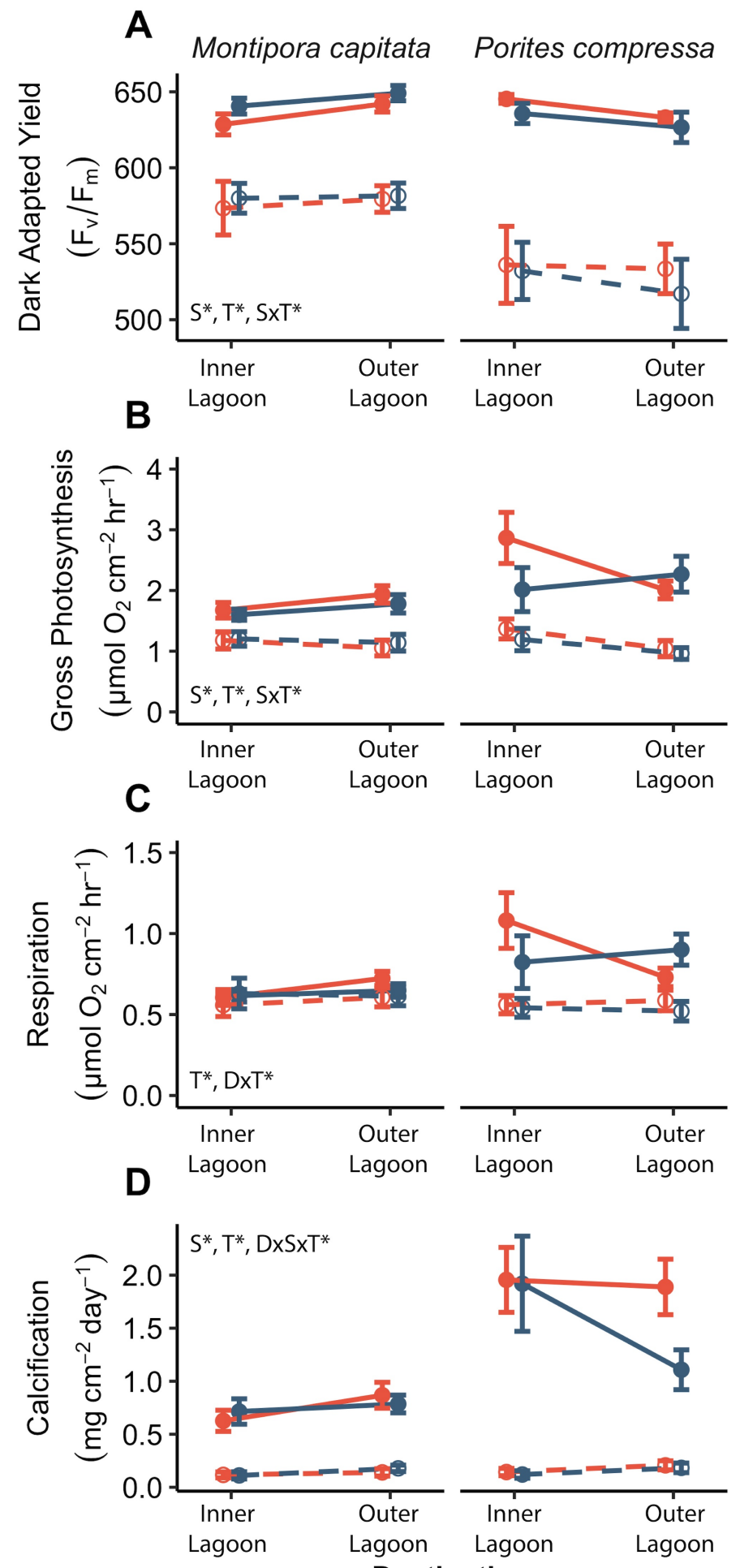

Destination

Figure 3. Coral performance following acute thermal stress (high temperature; $32^{\circ} \mathrm{C}$ ) vs. controls (ambient temperature; $27-28^{\circ} \mathrm{C}$ ). A) Photosynthetic efficiency (dark adapted yield; error bars indicate SEM. 

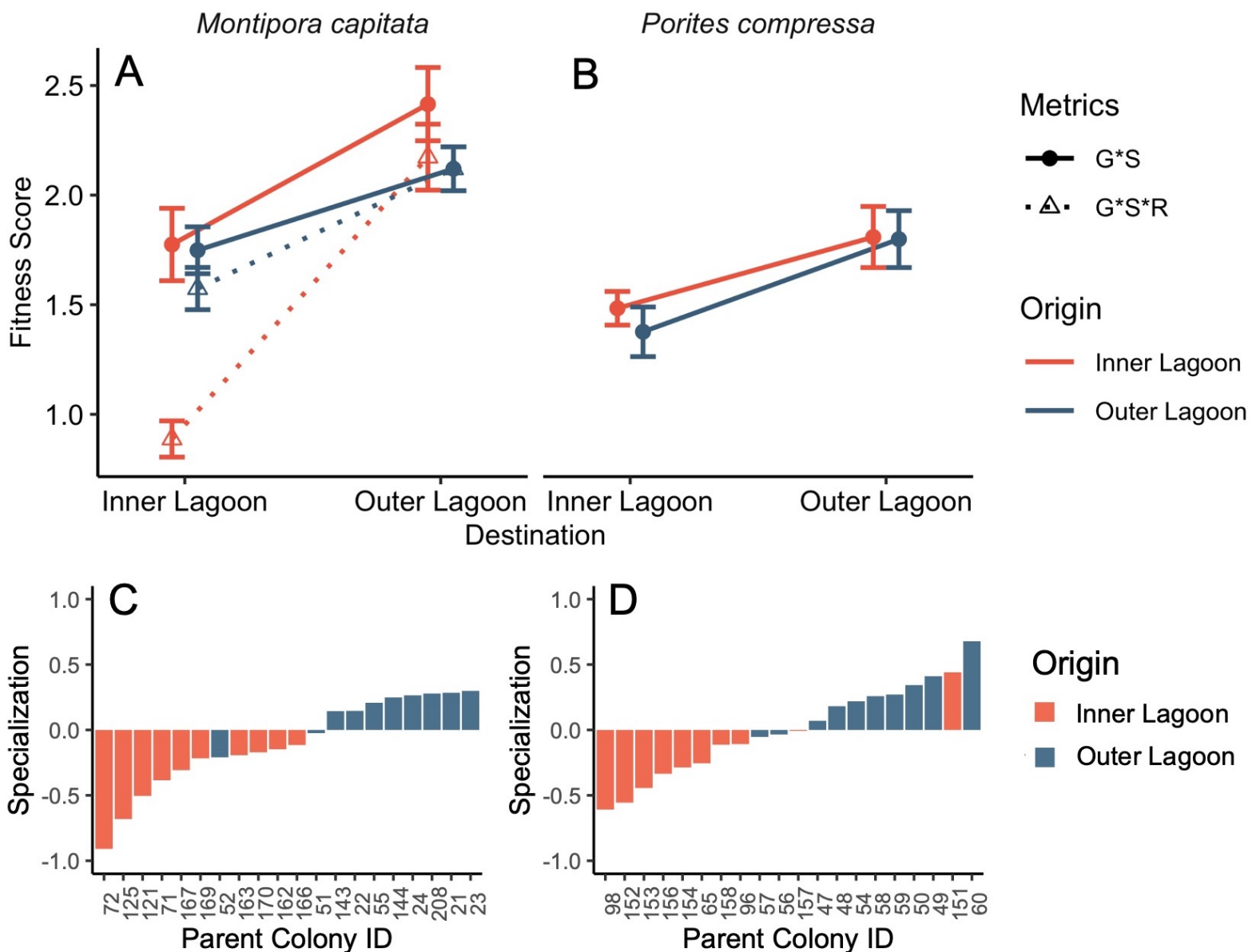

Figure 4. Fitness score for A) Montipora capitata and B) Porites compressa. Fitness score is a product of survival (S), net growth $(\mathrm{G})$, and for $M$. capitata, reproductive success $(\mathrm{R})$. $\mathrm{N}=10$; error bars indicate SEM. Magnitude of local specialization for each genet of C) M. capitata and D) $P$. compressa. Local specialization values are defined as the difference in fitness score $\left(\mathrm{G}^{*} \mathrm{~S}\right.$ only) of a genet at its origin and destination reef, divided by the mean fitness score of all conspecifics at the destination reef. Positive values indicate local site specialization; negative values indicate destination reef favorable. 

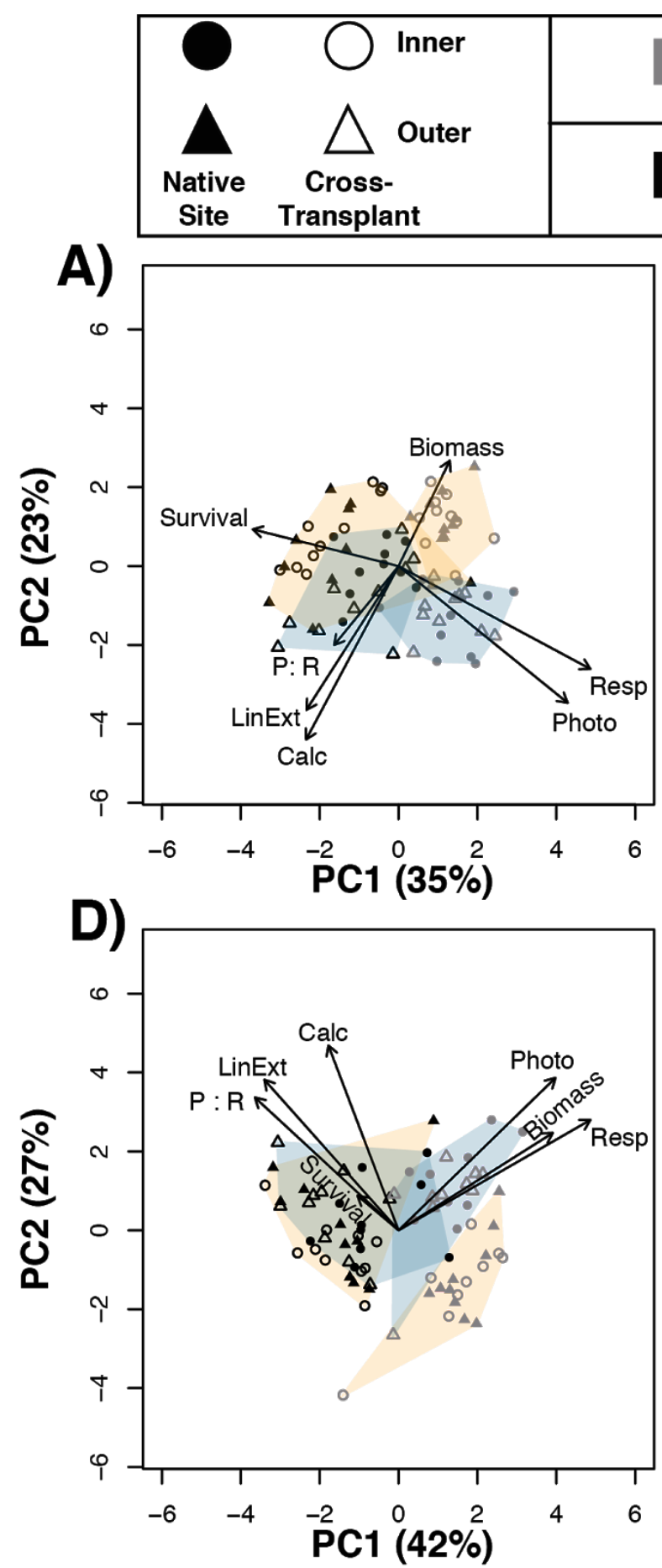

\begin{tabular}{|c|c|}
\hline P. compressa & $\begin{array}{l}\text { Inner } \\
\text { Outer }\end{array}$ \\
\hline M. capitata & $\begin{array}{l}\text { Inner } \\
\text { Outer }\end{array}$ \\
\hline
\end{tabular}
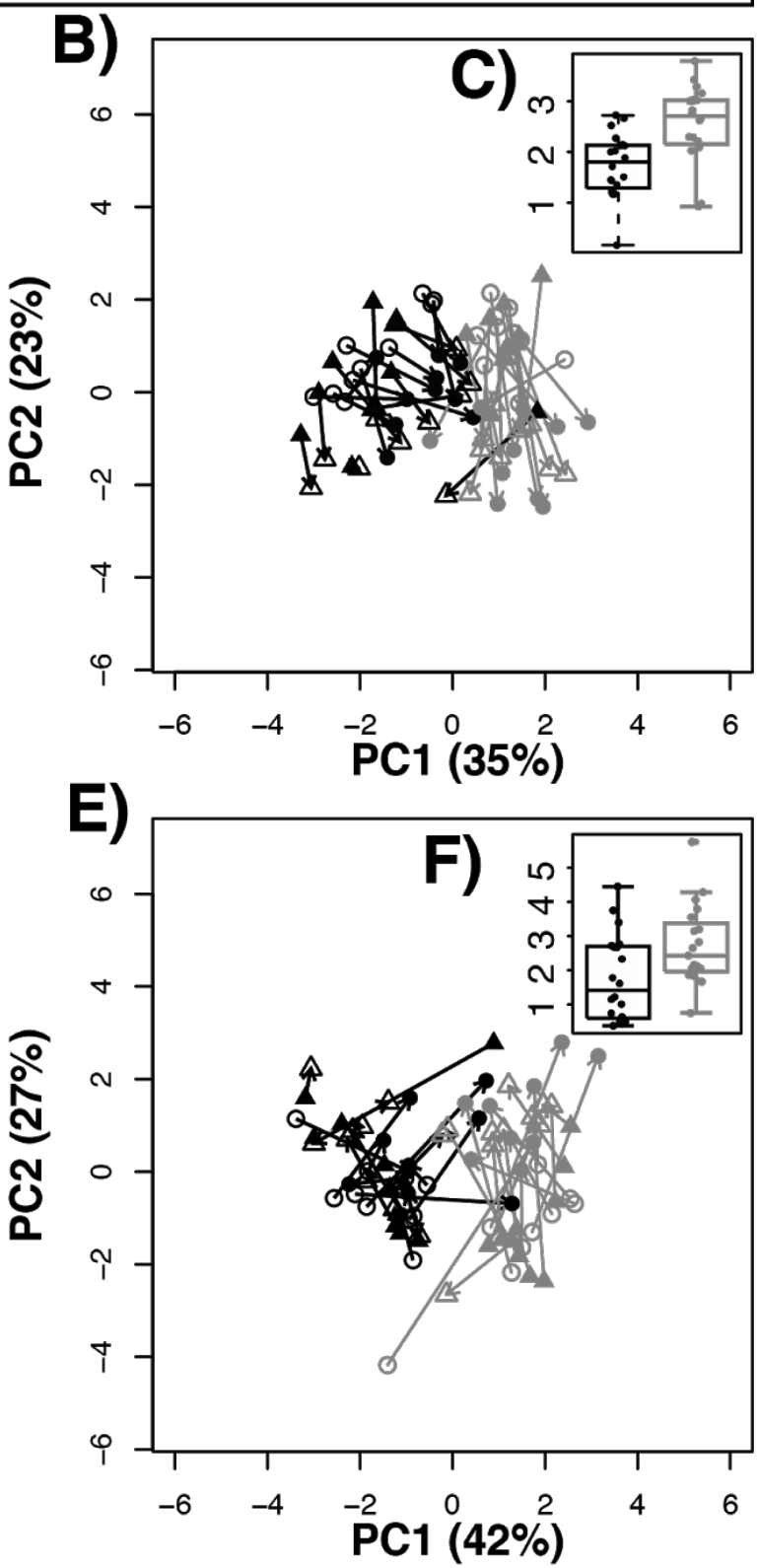

Figure 5. Principal component analysis of coral performance following three (A-C) and six months (D-F) of transplantation. Polygons outline the ordination groups, with Porites in purples and Montipora in greens, whereas vectors in (A) and (D) indicate the loadings of the phenotypic variables to the PCs, with length of arrow signifying strength of loading. Plasticity, calculated as the distance in principal component space between each genet's native (filled symbols) vs. crosstransplanted phenotype (open symbols) are indicated by lines in (B) and (E). The boxplots and data points for plasticity values of each species are shown in $(\mathrm{C})$ and $(\mathrm{F})$. 

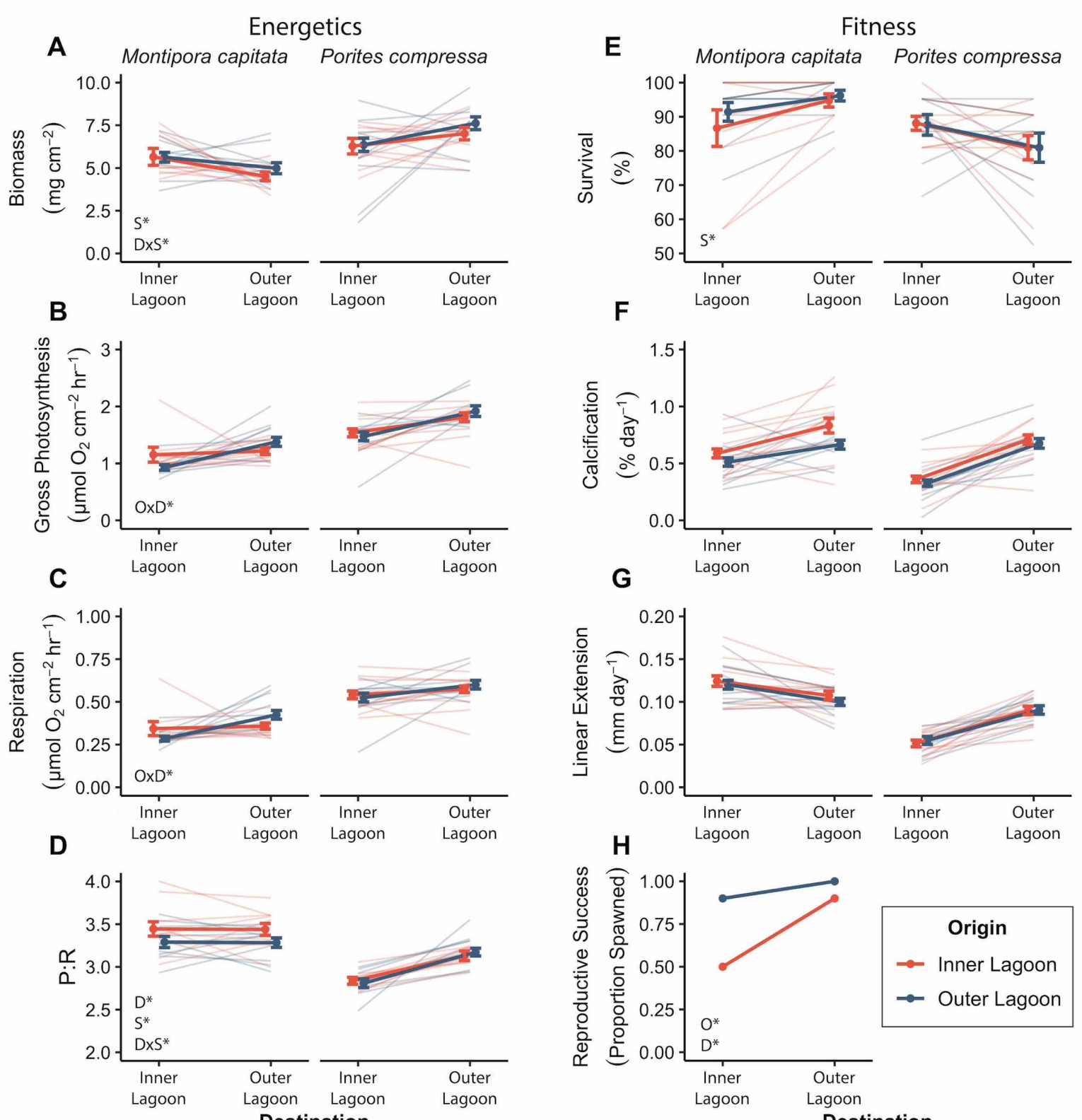

978 Figure 6. The effects of origin site and transplant site on coral energetics (left) and fitness (right) traits after 6 months following reciprocal transplantation of Montipora capitata and Porites compressa between an Inner and Outer Lagoon reefs. A) Biomass; B) Gross photosynthesis; C)

981 Respiration; D) Photosynthesis to respiration ratio (P:R); E) Survival; F) Calcification; G) Linear extension; and H) Reproductive success. Bold lines indicate the mean of all genets $(\mathrm{N}=10) \pm$ standard error of the mean (SEM); thin lines indicate mean response of each genets $(\mathrm{N}=5$ ramets). 